Full Length Article

\title{
Developmental neurotoxicity of MDMA. A systematic literature review summarized in a putative adverse outcome pathway
}

\author{
Marta Barenys $^{\mathrm{a}, *}$, Ingrid Reverte ${ }^{\mathrm{b}, \mathrm{c}}$, Stefan Masjosthusmann ${ }^{\mathrm{d}}$, Jesús Gómez-Catalán ${ }^{\mathrm{a}}$, Ellen Fritsche ${ }^{\mathrm{d}, \mathrm{e}}$ \\ ${ }^{\text {a }}$ GRET, INSA-UB and Toxicology Unit, Pharmacology, Toxicology and Therapeutical Chemistry Department, Faculty of Pharmacy, University of Barcelona, 08028 \\ Barcelona, Spain \\ ${ }^{\mathrm{b}}$ Department of Physiology and Pharmacology, Sapienza University of Rome, Rome, Italy \\ ${ }^{\mathrm{c}}$ Santa Lucia Foundation (IRCCS Fondazione Santa Lucia), Rome, Italy \\ ${ }^{\mathrm{d}}$ IUF - Leibniz Research Institute for Environmental Medicine, 40225 Düsseldorf, Germany \\ ${ }^{\mathrm{e}}$ Heinrich-Heine University, 40225 Düsseldorf, Germany
}

\section{A R T I C L E I N F O}

\section{Keywords:}

Neurodevelopment

Amphetamine derivative

Pregnancy

AOP

Motor function

Epidemiological ToxRTool

\begin{abstract}
A B S T R A C T
The increasing use of illegal drugs by pregnant women causes a public health concern because it is associated with health risks for mothers and their developing children. One of such drugs is MDMA (3,4-methylenedioxymethamphetamine) or ecstasy due to its high consumption in relevant age and sex groups and its adverse effects on human and rodent developing brains. To thoroughly review the current knowledge on the developmentally neurotoxic potential of MDMA we systematically collected and summarized articles investigating developmental neurotoxicity (DNT) of MDMA in humans and animals in vivo and in vitro. In addition, we summarized the findings in a putative adverse outcome pathway (AOP). From an initial 299 articles retrieved from the bibliographic databases Web of Science, PubMed and DART, we selected 39 articles according to inclusion/exclusion criteria for data collection after title/abstract and full text screening. Of these 3 where epidemiological studies, 34 where in vivo studies in mice and rats and 2 were in vitro studies. The three epidemiological studies reported from the same longitudinal study and suggested that MDMA exposure during pregnancy impairs neuromotor function in infants. In rat, postnatal exposure towards MDMA also caused locomotor deficits as well as impaired spatial learning that might be associated with decreased serotonin levels in the hippocampus. In vitro MDMA caused cytotoxicity at high concentrations and effects on the serotonergic and neuritogenic alterations at lower concentrations which are in line with some of the in vivo alterations observed. Considering the adverse outcomes of developmental MDMA described in humans and in rodents we summarized the first putative AOP on developmental compound exposure leading to impaired neuromotor function in children. For generation of this AOP, MDMA exposure was taken as a model compound. In addition, we hypothesized a second AOP involving developmental disturbance of the dopaminergic system. However, further in vitro mechanistic studies are needed to understand the molecular initiating event(s) (MIE) triggering the downstream cascades and obtain consistent evidences causally linking the adverse outcome to effects at the cellular, organ and organism level.
\end{abstract}

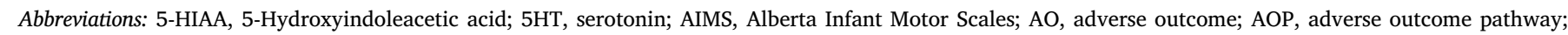

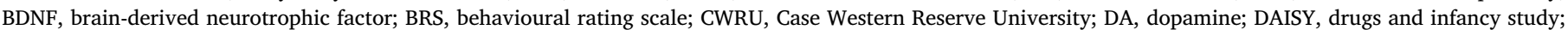

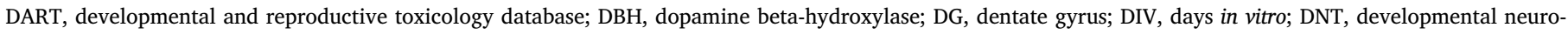

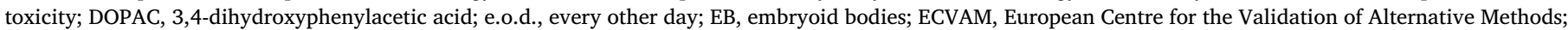

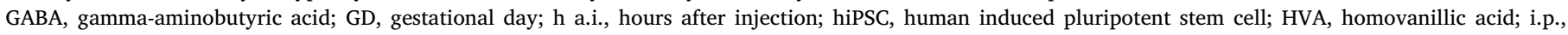

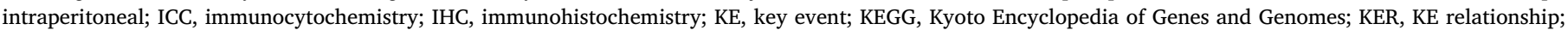

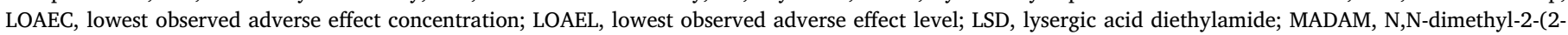

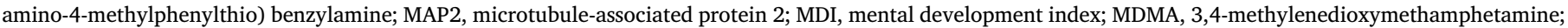

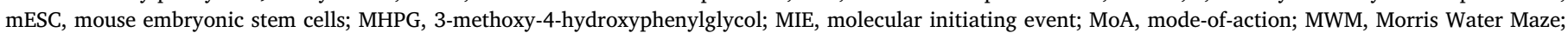

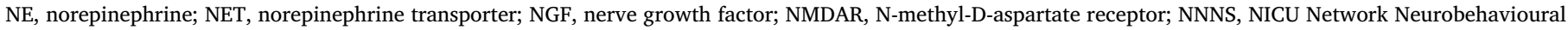

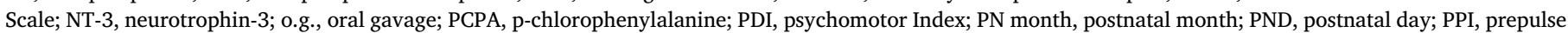
inhibition; s.c., subcutaneous; S.D., Sprague-Dawley; $\mathrm{TH}^{+}$, tyrosine hydroxylase; UEL, University of East London; W, weeks

* Corresponding author at: Department of Pharmacology, Toxicology and Therapeutic Chemistry, Faculty of Pharmacy and Food Sciences, University of Barcelona, 08028 Barcelona, Spain.

E-mail address: mbarenys@ub.edu (M. Barenys). 


\section{Introduction}

The period of highest risk for women to develop a substance use disorder overlaps with the childbearing age (18-44), especially between the ages 18 and 29 (Compton et al., 2007; Forray, 2016). Furthermore, the percentage of pregnant women using illicit drugs has been increasing over the last years. According to the National Surveys on Drug Use and Health of the United States, the percentage of pregnant women reporting consumption of illegal drugs in the month before the survey increased from $5.1 \%$ in 2008 to $8.5 \%$ in 2017 . Indeed, when focusing on the period of highest risk aforementioned (in this case 18-25 years of age) illicit drug use during the month before the survey reported by pregnant women even increased to $11.0 \%$ in 2017 (Substance Abuse and Mental Health Services Administration, 2018, 2009). Similar tendencies are observed in other countries, like Canada (Petrangelo et al., 2018), yet there is a huge gap of information on drug abusing women during pregnancy (EMCDDA, 2012). This is due to difficulties in data obtention most likely related to the social stigma associated with drug use during pregnancy.

Illicit drug use during pregnancy causes a public health concern because it is associated with increased health risks for the mother and the developing child. Which health adverse outcome is created largely depends on the substance consumed. For example, adverse effects related to prenatal exposure to legal drugs like alcohol are well described by lower birth rates, preterm birth or perinatal death (Bailey and Sokol, 2011) and fetal alcohol syndrome which includes intellectual disability, birth defects and characteristic dysmorphic facial features (Chudley et al., 2005). However, besides the data gap in exposure assessment, there is also little known on the adverse effects on development of many of the illicit drugs. One important example with sparse data yet public concern due to high consumption in the relevant age and sex group (EMCDDA, 2017) are amphetamine derivatives like MDMA (3,4-methylenedioxymethamphetamine).

MDMA or ecstasy or 'Molly' is a synthetic drug mainly consumed by teenagers and young adults for its psychotropic actions. These include psychostimulant and 'entactogen' effects enhancing emotional empathy and prosocial behaviour. Related to the entactogen effects of MDMA, several authors described that ecstasy users are more likely to engage in high risk sexual behaviours including casual and unprotected sex (Castilla et al., 1999; Mattison et al., 2001; May and Parrott, 2015; Palamar et al., 2018). MDMA users who become pregnant normally stop taking the drug after the first trimester, although some cases of prolonged consumption have also been described (Ho et al., 2001; Moore et al., 2010; Scott et al., 2010; Van et al., 1998).

Studies in pregnant rats demonstrated that MDMA crosses the placental barrier and reaches the fetal brain (Campbell et al., 2006). In addition, it was inferred that with a high probability MDMA is found in breast milk considering that it is a low-molecular-weight and hydrophobic molecule with a pKa of 10.4 (Cho et al., 2008). Several independent research groups observed adverse effects of MDMA on the developing rodent brain and few epidemiological or case report studies also described developmental neurotoxicity (DNT) of MDMA in humans. This drug has therefore been included in the list of reference compounds for alternative test methods to study their DNT potential (Aschner et al., 2017). However, the extent of the potential adverse outcomes and the mode-of-action(s) (MoA) underlying these DNT effects are enigmatic. So far, a variety of studies intended to clarify if the effects of MDMA on the developing nervous system are mediated through a similar MoA than adult neurotoxicity, i.e. causing disfunction of the serotonergic system, with serotonin depletion and loss of serotonin transporter (Parrott, 2013). Some of these studies point out that the DNT MoA might be completely different than the one for adult neurotoxicity, yet this is currently unclear.

For improved risk perception and thus prevention of harm, comprehensive information is necessary that clearly links MDMA exposure of women during pregnancy to adverse neurodevelopmental outcomes in children. As a first step, the aim of this review is to collect and summarize articles published until November 2018 on DNT effects of MDMA in humans and animals in vivo as well as in vitro. From these data, hypothetical/putative adverse outcome pathways (AOP) will be summarized that highlight the main common findings and importantly, points out the existing knowledge gaps. This approach will help accelerating the acquisition of new knowledge on MDMA-induced DNT, especially information on the MoA, which is urgently needed for a deeper understandning of dose-effect relationships and thus a hazard and risk assessment based on mechanistic understanding.

\section{Review methodology}

\subsection{Search method}

\subsubsection{Databases}

Literature search was performed in three databases covering different levels of specialization: 1) Web of Science: a multidisciplinary database including more than 34.200 journals, plus books, proceedings, patents, and data sets on the fields of biomedical sciences, natural sciences, engineering, social sciences, and arts and humanities (WebofScience); 2) PubMed: a biomedical database including literature from MEDLINE, life science journals, and online books (PubMed); 3) DART (developmental and reproductive toxicology database): a specific database belonging to the TOXNET database (toxicology data network) from the U.S. National Library of Medicine and including "journal references covering teratology and other aspects of developmental and reproductive toxicology" (DART). The information gathering procedure used in this study is summarized in Fig. 1.

\subsubsection{Keywords}

Searches performed in Web of Science and PubMed included two groups of truncated keywords: keywords related with "developmental neurotoxicity/exposure" AND "names and synonyms of MDMA and MDMA $\mathrm{HCl}$ obtained from ChemIDPlus (ChemIDplus)"; while the search performed in DART only included "3,4-Methylenedioxymethamphetamine" name, as this database recognized the chemical name and automatically added synonyms and CAS number retrieved from ChemidPlus. The search in DART did not include the "developmental neurotoxicity/exposure" group of keywords because this database is already selective for references related to developmental toxicology. DART search was restricted to not include PubMed results to avoid duplicates (exclusion of the default option "Include PubMed Results"). The exact syntax with all keywords used in the three searches is detailed in Supplementary Information file 1. Timespan was not limited in any of the searches.

\subsection{Exclusion criteria}

All references obtained from the three searches (Web of Sciences: 


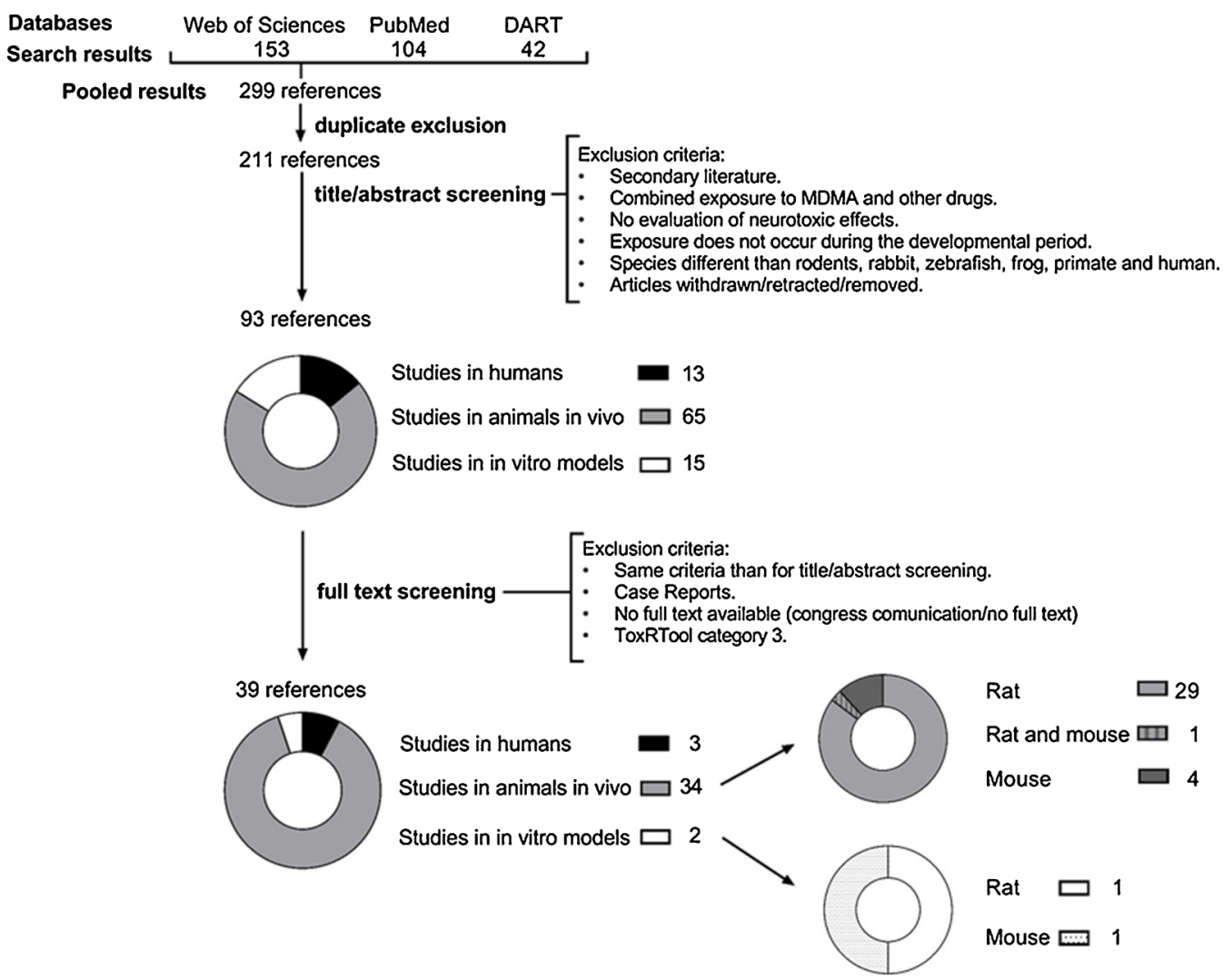

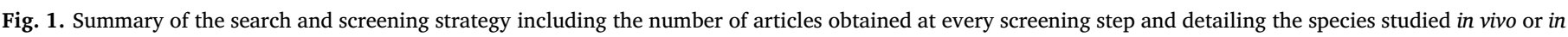
vitro in each article. No in vitro studies based on human cells were found.

153, PubMed: 104, DART: 42) were exported to a common Mendeley library (299 references). After excluding duplicates, 211 remaining articles were further screened based on title and abstract according to the following exclusion criteria:

- Secondary literature.

- Combined exposure to MDMA and other drugs.

- No evaluation of neurotoxic effects.

- Exposure does not occur during the developmental period (defined as gestational period in human studies, as gestation and lactation up to postnatal day 21 in rodent studies, and as exposure during cell differentiation for in vitro studies).

- Species different than rodents, rabbit, zebrafish, frog, primate and human.

- Articles withdrawn/retracted/removed.

A total of 118 articles were excluded according to these criteria leaving 93 articles for full text screening.

\subsection{Classification and retrieval of selected studies}

Selected 93 studies were classified in three groups: studies on the DNT of MDMA (1) in humans in vivo, (2) in animals in vivo, and (3) in in vitro models.
Full-text copies of the references included in groups 1, 2 and 3 were obtained from the following university libraries: Heinrich-HeineUniversität Düsseldorf, Universitat de Barcelona and Sapienza University of Rome and Fondazione Santa Lucia.

\subsection{Information acquisition from full texts and harmonized evaluation of methodological quality}

Full texts of the studies (13 from group 1, 65 from group 2 and 15 from group 3) were read and respective detailed study data gathered in a working table. While reading the full-text, article quality was evaluated and categorized using the "ToxRTool" (Schneider et al., 2009) available on the ECVAM website (http://ecvam.jrc.it, section "Publications"). This publicly available tool developed in Microsoft Excel ${ }^{\circledR}$ is based on the approach of Klimisch et al. (1997) to assess the reliability of toxicological data. The tool was used to harmonize the reliability assessment within the working group. The ToxRTool consists of two different excel sheets, one for in vivo and one for in vitro data, which were used for all studies included in groups 2 and 3, respectively. The criteria for these studies are grouped in: I) Test substance identification; II) Test system/organism characterization; III) Study design description; IV) Study results documentation; V) Plausibility of study design and results.

To the best of our knowledge, there is no ToxRTool available for 
evaluating the quality of human epidemiological studies. Therefore, we developed our own ToxRTool for these studies based on two guidelines for DNT risk assessment (Environmental Protection Agency, 1991; Travis et al., 2008). Criteria extracted from these guidelines were grouped following the same five categories as of the ToxRTool for in vivo and in vitro studies. This newly developed ToxRTool is available as a Supplementary information file 2 .

While reading the full-text of the articles, inclusion/exclusion of studies to the review was revised based on the same six criteria presented in Section 2.2 plus exclusion criteria "ToxRTool Category 3: not reliable" and single case report studies. Fig. 1 summarizes the number of full-texts reviewed and the number of articles finally included/excluded in this review.

\section{Results and discussion}

\subsection{Neurodevelopmental effects of prenatal exposure to MDMA in humans}

A total of 13 human studies were identified by the systematic search. Ten of them were excluded for the following reasons: five because they were conference abstracts, one because it did not evaluate DNT, two because it was secondary literature, one because of low quality score in the ToxRTool (category 3 ) and one for being a single case report. The results of the three selected ones are summarized in Table 1.

Limited evidence is available on the neurodevelopmental effects of prenatal exposure to MDMA in humans. To the best of our knowledge, there is only one prospective epidemiological study evaluating neurobehavioural parameters in infants from birth up to 2 years of age after intrauterine exposure to MDMA. This longitudinal study resulted in 4 publications: the first describes the profile of drug intake of the mothers and will not be discussed here as it is not the focus of the present review (Moore et al., 2010); the second monitors the neurobehavioural outcomes of the infants at 1 and 4 months of age (Singer et al., 2012a); the third one describes the behavioural outcomes at one year of age (Singer et al., 2012b); and the fourth one compares the outcomes in a longitudinal study across the children at 1, 4, 12, 18, and 24 months of age (Singer et al., 2016). The results of this study suggest that MDMA exposure during pregnancy impairs neuromotor function in infants. Below, we describe in detail the results of this epidemiological work and provide insights in its limitations and directions to be taken in human research of prenatal exposure to MDMA.

The prospective study of Singer and colleagues compared a cohort of 28 mothers who consumed MDMA during pregnancy with 68 mothers who did not. Regardless of their MDMA intake, all of them had a history of polydrug use and continued to use other substances during pregnancy. Mothers were recruited mainly through paid adverts as a part of the Case Western Reserve University (CWRU) and University of East London (UEL) Drugs and Infancy Study (DAISY) in the UK. The neurodevelopmental outcomes of the infants were monitored from birth to 2 years of age using a battery of standardized developmental scales that evaluate motor and cognitive functions (Singer et al., 2012a).

The main effect observed in MDMA-exposed infants was a motor delay detected as early as 1 month after birth, which persisted until 24 months of age. This effect manifested subtly at 1-month of age as a trend to more lethargic behaviours and hypotonia as measured by the NICU Network Neurobehavioural Scale (NNNS). The motor delay became more evident at 4 months of age, where MDMA-exposed children showed poorer motor quality in the Motor Quality Scale of the Behavioural Rating Scale (BRS) of the Bayley Development Scales and lower performance on the Alberta Infant Motor Scales (AIMS). Both of these scales measure gross motor maturation. Particularly, MDMA-exposed infants showed less coordination and more slow and delayed movements, and notably, this effect was dose-dependent (heavier vs lighter MDMA users; Singer et al., 2012a).

At 12 months of age, consistently with the early findings, MDMAexposed children showed a lower Psychomotor Index (PDI) of the Bayley Development Scales, an index of gross and fine motor control and coordination. A third of the highly exposed children displayed a significant developmental delay (PDI $<70$ ) while the remaining were at risk (PDI $<85$ ). In comparison, only $10 \%$ of the lighter and nonexposed children showed a significant delay and a third were at-risk. The lower PDI was maintained in heavily exposed children at 18 and 24 months of age (Singer et al., 2012b). Importantly, MDMA exposure did not affect the cognitive domain. A lower Mental Development Index (MDI) was observed in children at 12 months of age; however, the authors hypothesized that this effect could be related to the deficit of fine motor skills (Singer et al., 2012b). This effect was no longer observed at later ages, and no other effects on language, emotional regulation or attention were observed (Singer et al., 2016).

Another effect of MDMA exposure reported by Singer et al. (2012a) is that MDMA-exposed infants were significantly more likely to be male (71\% vs. $46 \%)$. Yet, the number of individuals is too low to draw a definite conclusion on MDMA effects on sex determination. They did not observe differences in other perinatal variables such as gestational length or probability of stillbirths, neither on other physical characteristics of the babies at birth (ie. birthweight, birth length; Singer et al., 2012a).

The results described in the UK cohort demonstrate a robust and reliable effect of prenatal MDMA exposure on motor development, evidenced by the fact that motor delay was detected by different developmental scales and sustained through age. Additionally, the effects were statistically significant despite the small sample size after controlling for multiple confounding factors, including home environment, maternal stress and exposure to other drugs. It is important to note that all women included in the study reported to use MDMA during the first two trimesters, decreasing its use as the pregnancy advanced, while only one woman kept consuming during the 3rd trimester. Therefore, the motor effects observed can be attributable to exposures during the beginning and middle of pregnancy. Additional studies are necessary to evaluate the effects of MDMA exposure during the third trimester, which is not likely to be possible using epidemiological studies. Furthermore, little is known about potential interactions between drugs in polydrug users. In the UK cohort, women who took MDMA during pregnancy were more likely to also take marijuana, cocaine, LSD, and mushrooms while pregnant (Moore et al., 2010; Singer et al., 2016).

Taken all this together, more studies concerning prenatal exposure to MDMA are needed and a few considerations have to be taken into account. Despite the robustness of the UK cohort study, the sample of MDMA users, especially when divided between light $(n=15)$ and heavy users ( $n=13$; division based on a median split), was small. Recruiting larger samples is important to detect small effects with high variability, such as more subtle neurodevelopmental outcomes. Besides the inherent variability of neurodevelopmental parameters, another source of variation concerns the usage of MDMA between pregnant mothers with regards to duration, quantity or patterns of intake, which 


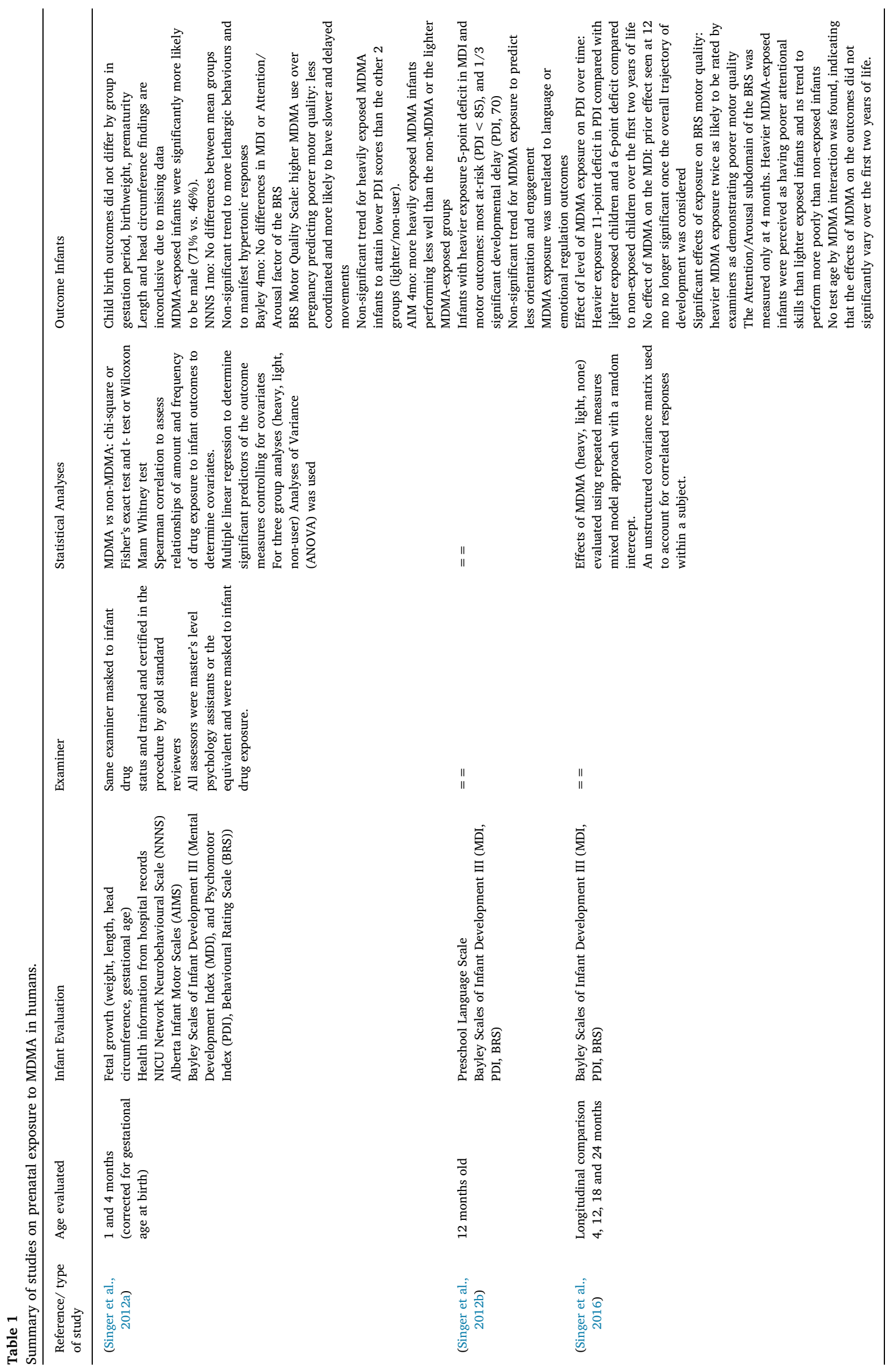




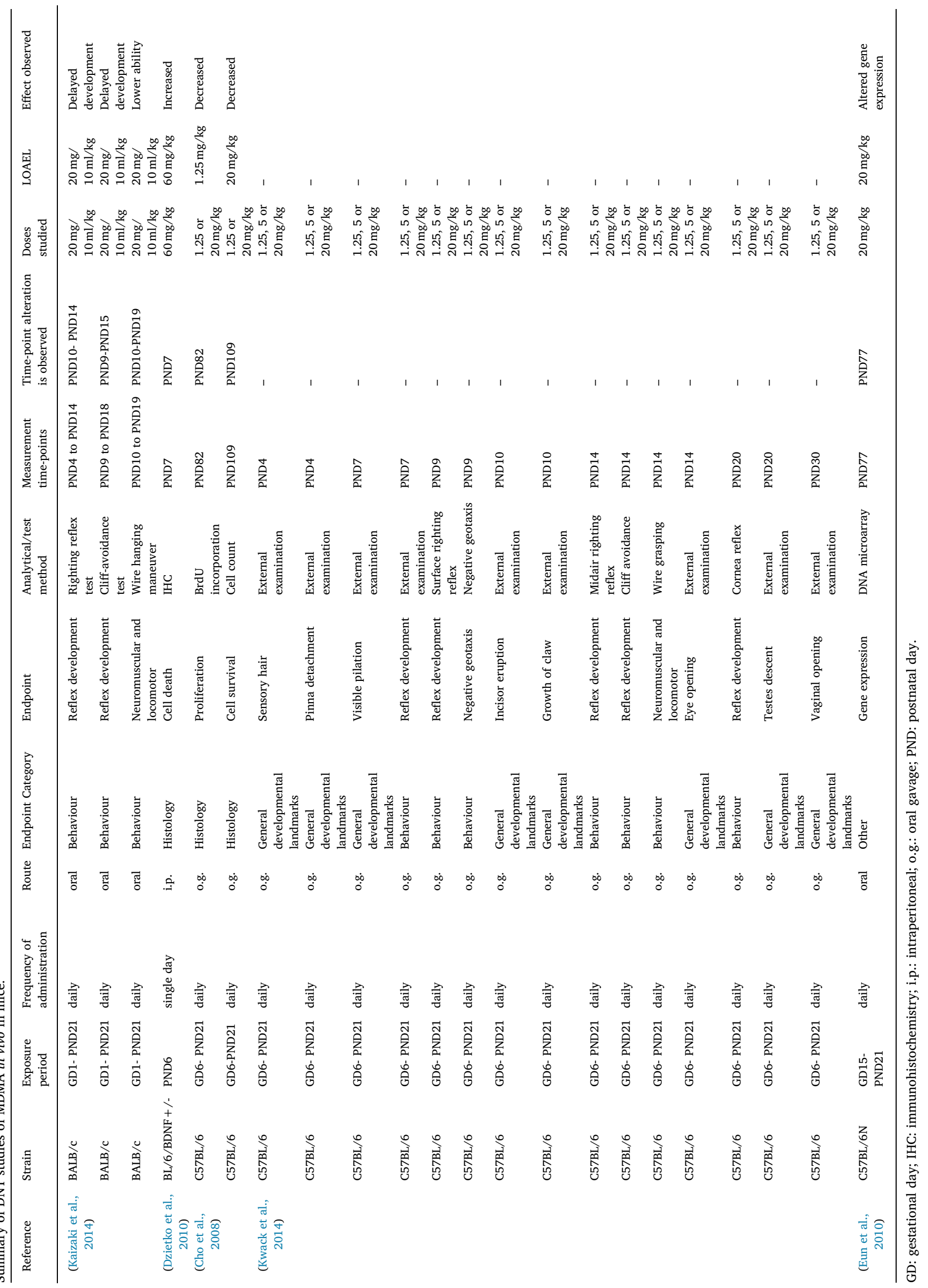




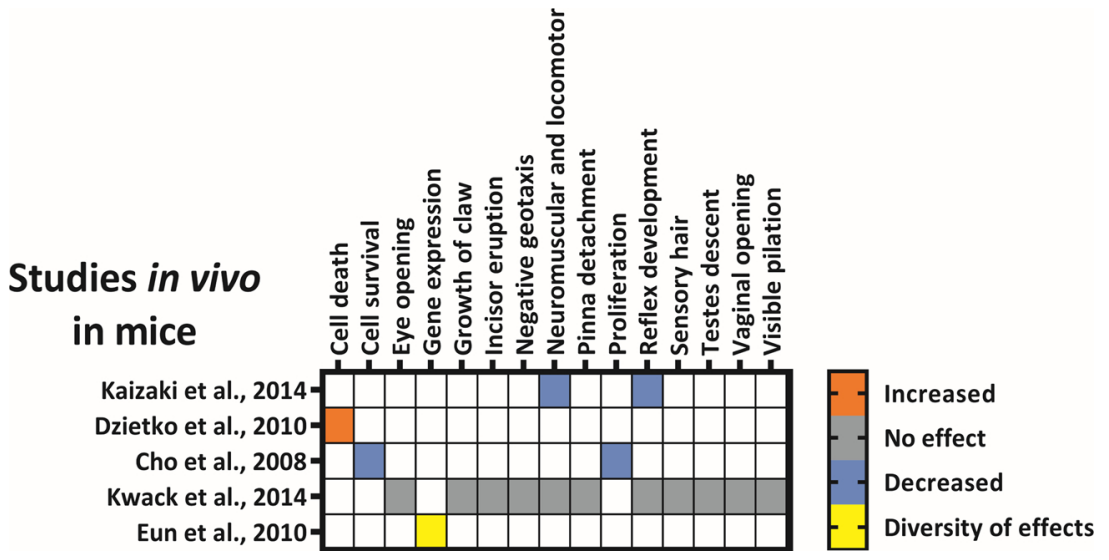

Fig. 2. Heatmap summarizing the information about DNT studies of MDMA in vivo in mice collected in Table 2. Endpoints measured in a particular study are indicated with colored cells depending on the effect observed (increase - orange, decrease - blue, diverse effects - yellow) or the absence of effect (grey). For more information about the details of each specific study, readers are referred to Table 2. will in turn contribute to raise the variability in children outcomes. However, collecting large samples may be challenging because of social stigma associated to drug use, especially during pregnancy. As reported by the authors of the UK study this was a major drawback in recruiting subjects for their study. Another consideration refers to the method of exposure estimation. Although self-report may often be the only tool available to estimate drug intake, pregnancy follow-ups using hair or other biological samples would aid to validate self-reported usage and provide more accurate dosage estimates. Last, including a non-drug user control besides the polydrug control would be ideal to disregard effects of other drug exposure.

\subsection{Neurodevelopmental effects of developmental exposure to MDMA in animals in vivo}

After the title and abstract screening, 65 articles on in vivo animal studies were included in the review. Full texts were collected and read for further evaluation according to the exclusion criteria and the ToxRTool - in vivo. From this analysis, 31 articles were excluded for the following reasons: one was a duplicate, two were secondary literature, three were not evaluating DNT, twenty-two were congress communications, one was excluded because of low quality (ToxRTool category 3 ), and two because the full-text could not be obtained.

All remaining 34 studies included in this group were performed in rodents, with 30 rat and 5 mouse studies (one study including both). Such a different proportion in the number of studies amongst these two species might be related to the knowledge acquired from adult neurotoxicity studies; adult neurotoxicity of MDMA is species-specific with induction of selective damage to serotonergic neurons in rats as well as most species examined including non-human primates (Green et al., 2003; Steele et al., 1994) and in contrast selective dopaminergic neurotoxicity in mice (O'Callaghan and Miller, 1994). According to Mueller et al. (2013), these different neurotoxicity profiles cannot be explained by differences in MDMA metabolism or pharmacokinetics of rats and mice. Probably, as the basis for these inter-species differences remain unknown, most study designs for developmental MDMA exposure choose rats because these belong to the rodent species which displays the most similarity in adult neurotoxicity to primate species.

Besides using different species, a huge variety of experimental designs was applied in the animal in vivo studies. For a comprehensive review on the large methodological diversity and little consistency among preclinical studies assessing the effects of amphetamine-type stimulants (including MDMA) during pregnancy and lactation the reader is referred to McDonnell-Dowling and Kelly (2015). In this article the high variability of doses administered in studies evaluating developmental effects of MDMA is also discussed. In general, MDMA doses administered in animal studies are much higher than the ones regularly taken by young recreational ecstasy users. However, it has been proven that the application of common interspecies scaling strategies to compare MDMA doses between rodents and humans are not valid because in humans MDMA has a saturable kinetics (de la Torre et al., 2000). Thus, according to toxicokinetic studies in humans and rats reviewed by Green et al. (2009), to produce a similar peak blood plasma to that seen in humans after a $2 \mathrm{mg} / \mathrm{kg}$ dose, four fold higher doses are required in rats. Besides, the rapid MDMA clearance in this rodent species is also used by some authors to explain that repeated injections in rats would be the best strategy to mimic single oral doses in humans. Despite the large methodological heterogeneity observed in doses, number of administrations per day and exposure period, we present a summary of the results focusing on common adverse outcomes observed in rodent studies.

Of the five studies performed in mice (Table 2 and Fig. 2), three used a similar pattern of exposure: from fertilization or implantation to the end of lactation (gestational day (GD)1 or GD6 to postnatal day (PND)21) with one oral administration daily and a common maximum dose of $20 \mathrm{mg} / \mathrm{kg}$ b.w. (Cho et al., 2008; Kaizaki et al., 2014; Kwack et al., 2014). Cho et al. (2008) evaluated the effects of MDMA on neurogenesis using histological methods. They found a decreased number of BrdU labeled cells in the dentate gyrus $24 \mathrm{~h}$ or 28 days after BrdU administration, indicating that developmental exposure to MDMA decreases the proliferation and survival of cells in the dentate gyrus. This observation is supported by similar findings in an acute dosage study with three i.p. doses of MDMA on PND6. In particular, they observed an increased cell degeneration determined by stereological cell counts in many of the 17 brain regions analyzed, specially in the frontal, parietal and cingulate cortices, the septum, thalamus, hypothalamus and the cornu ammonis 1 region of the hippocampus. However, this effect was observed $24 \mathrm{~h}$ after the exposure but not after 14 or 21 days (Dzietko et al., 2010). The other two studies with long gestational and postnatal exposure to MDMA evaluated different 


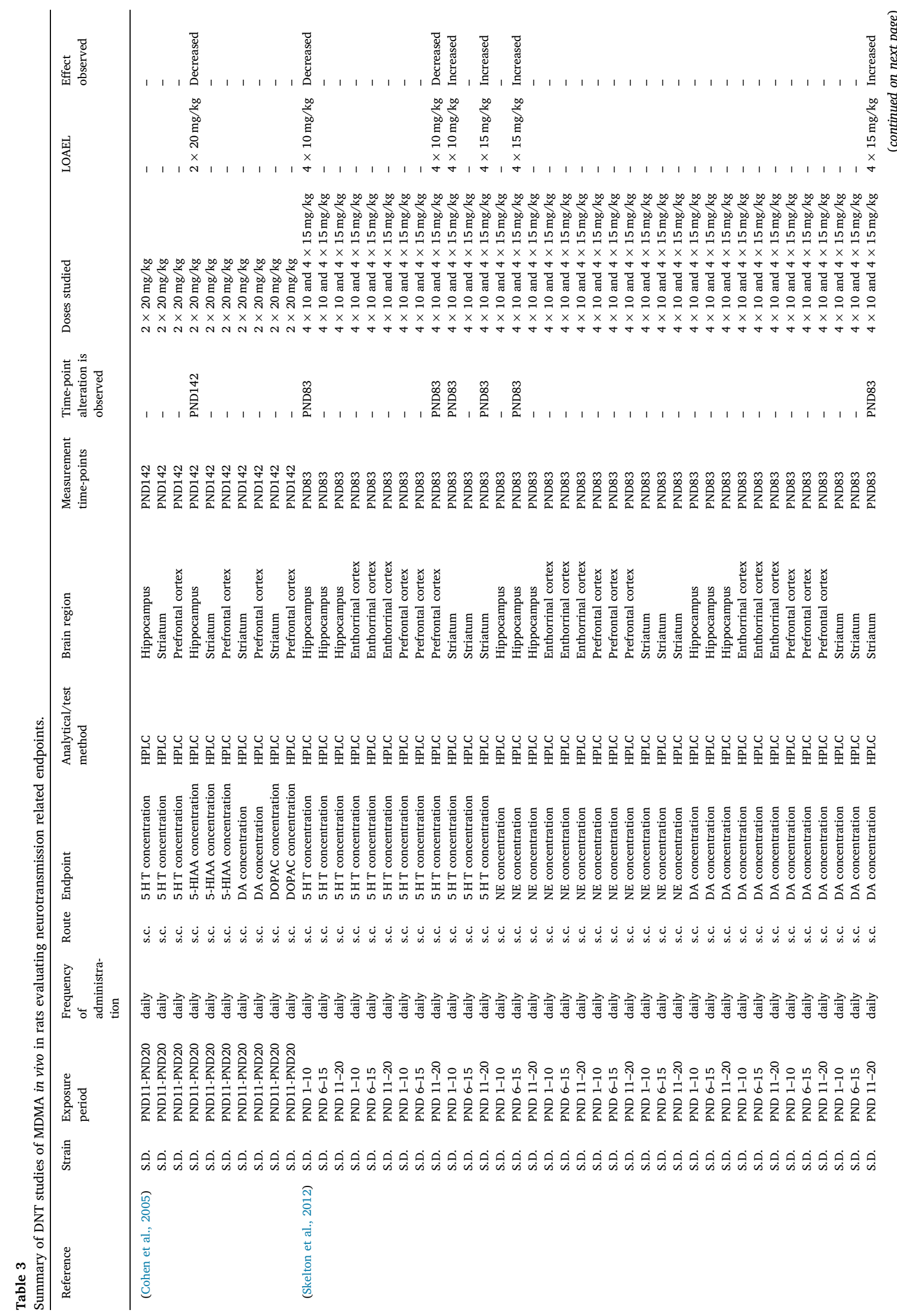




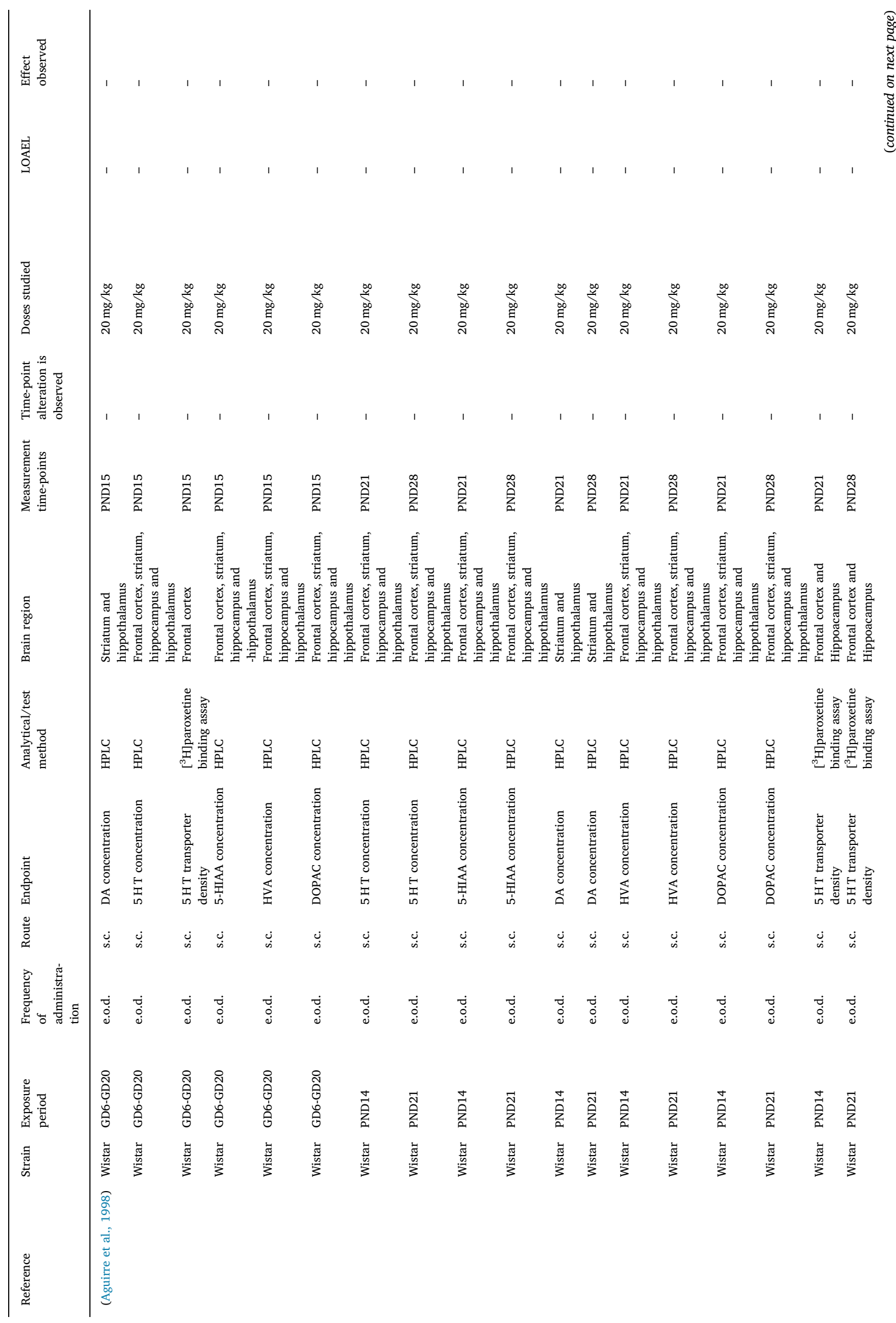




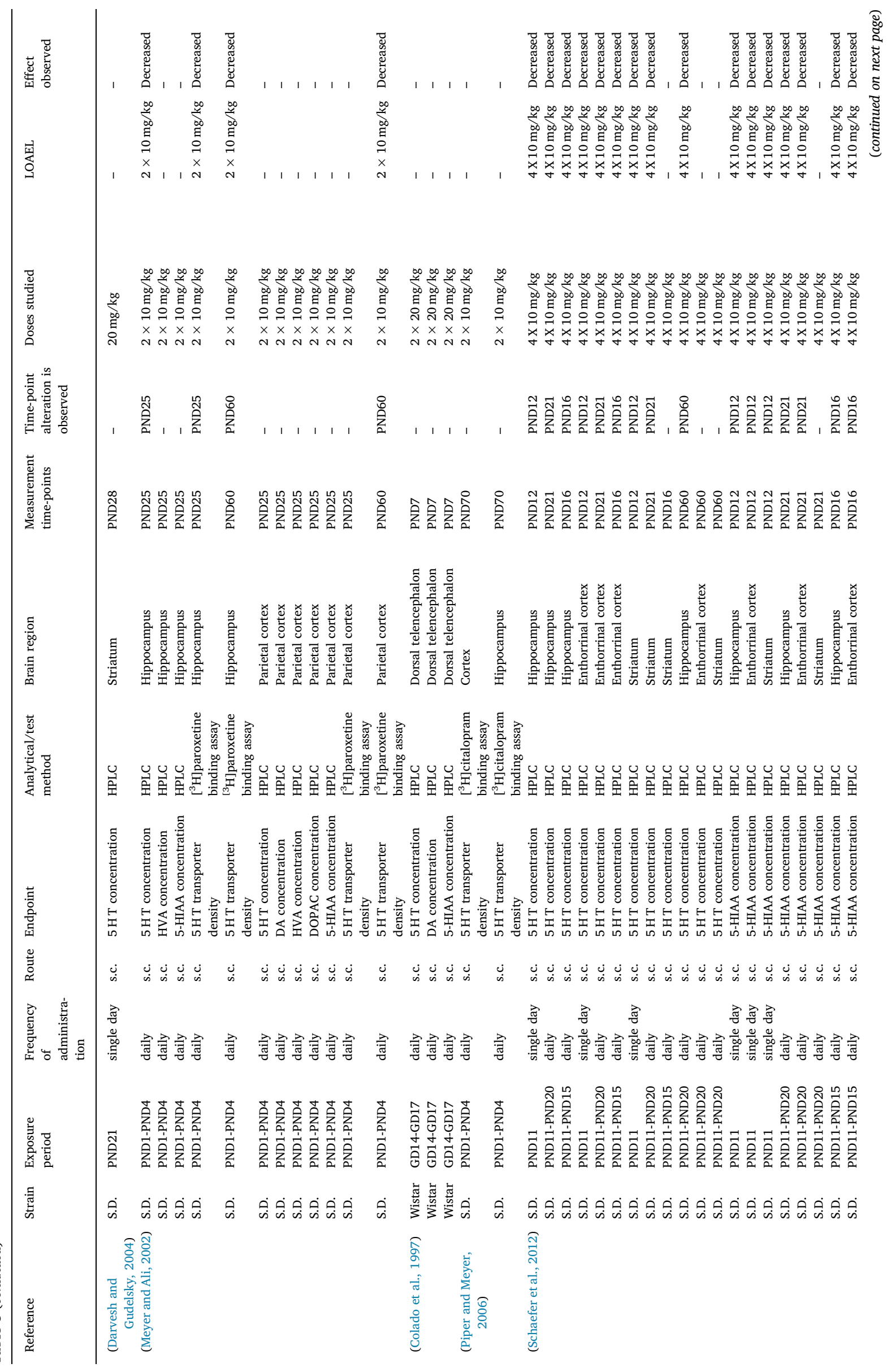




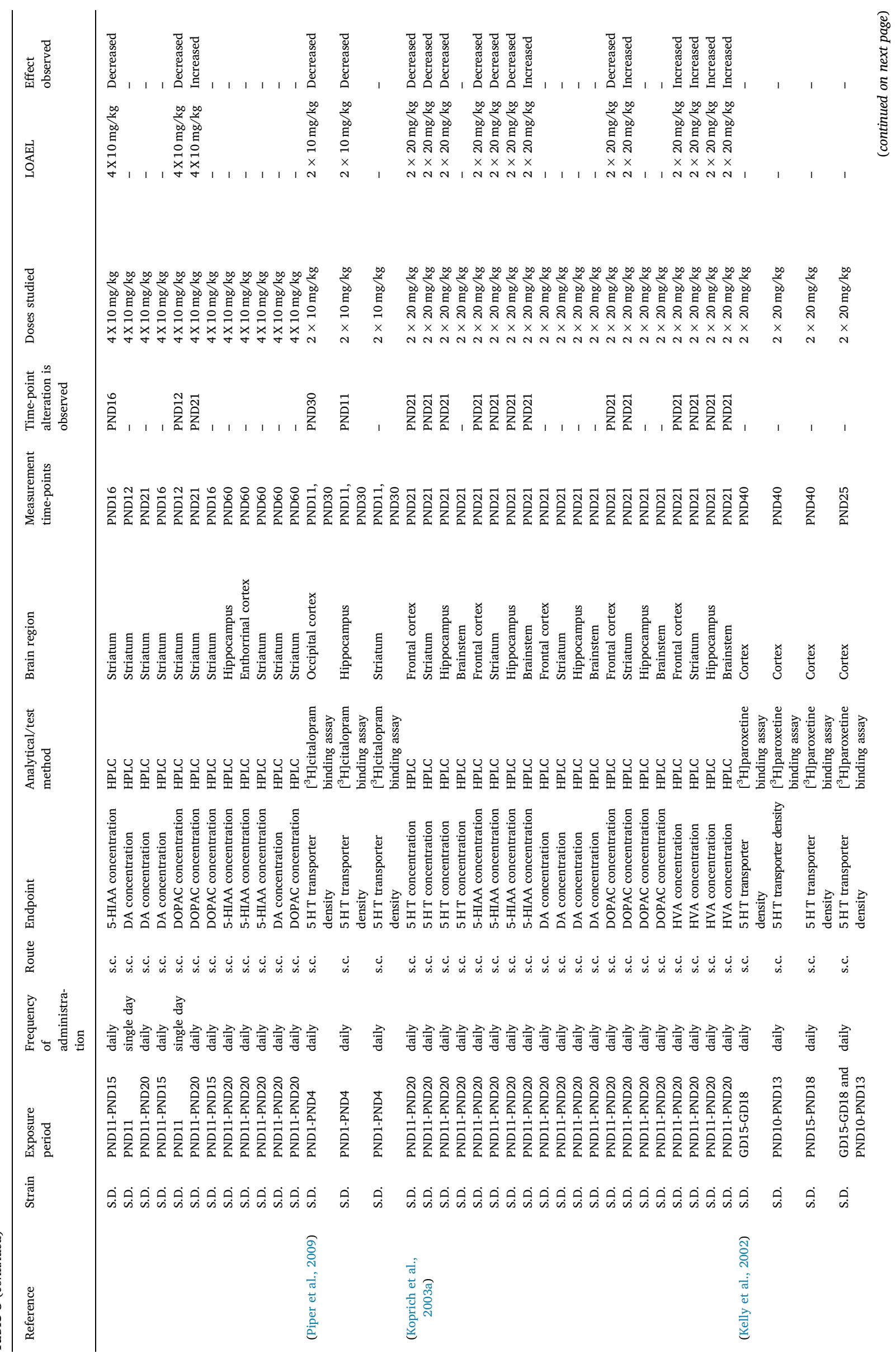




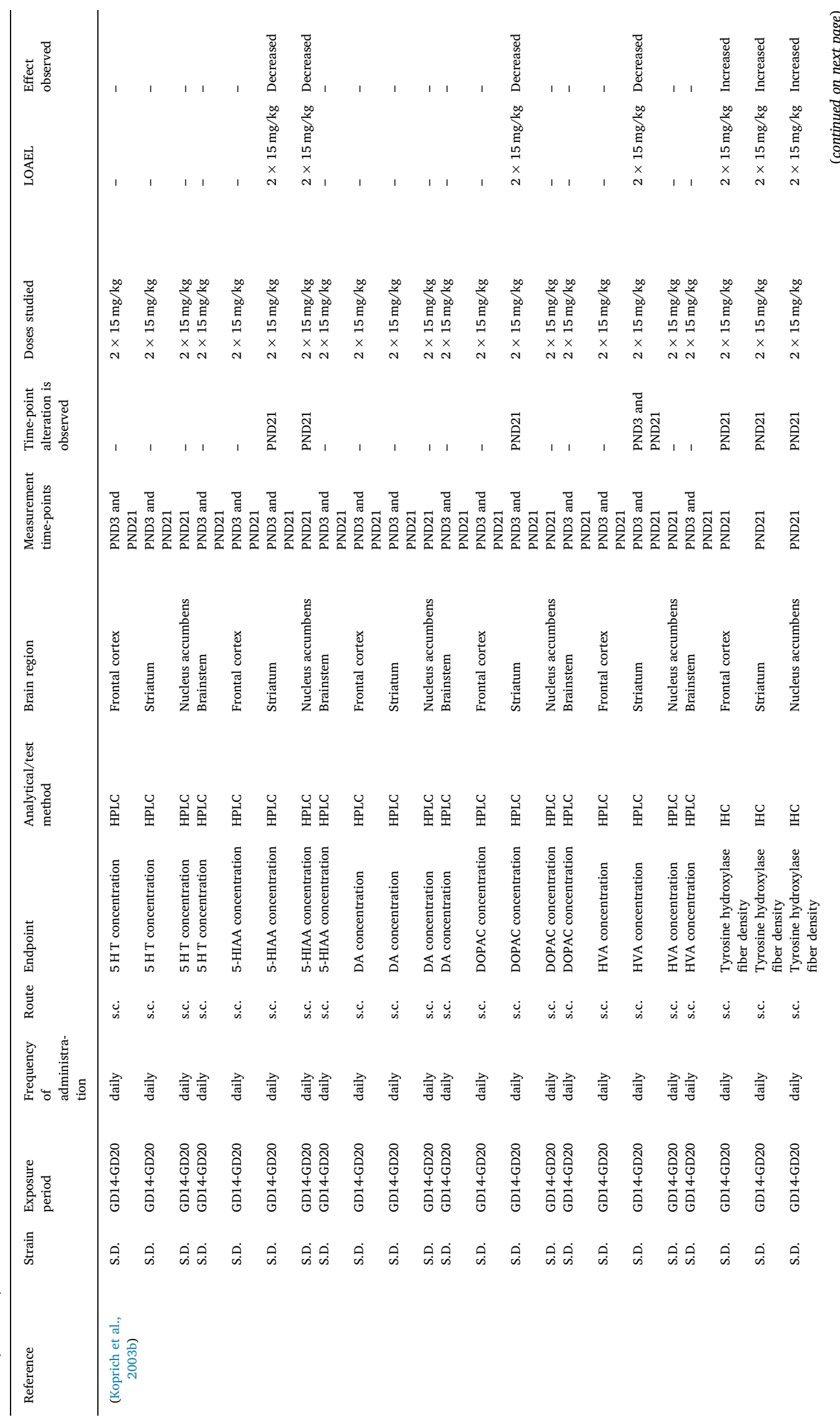




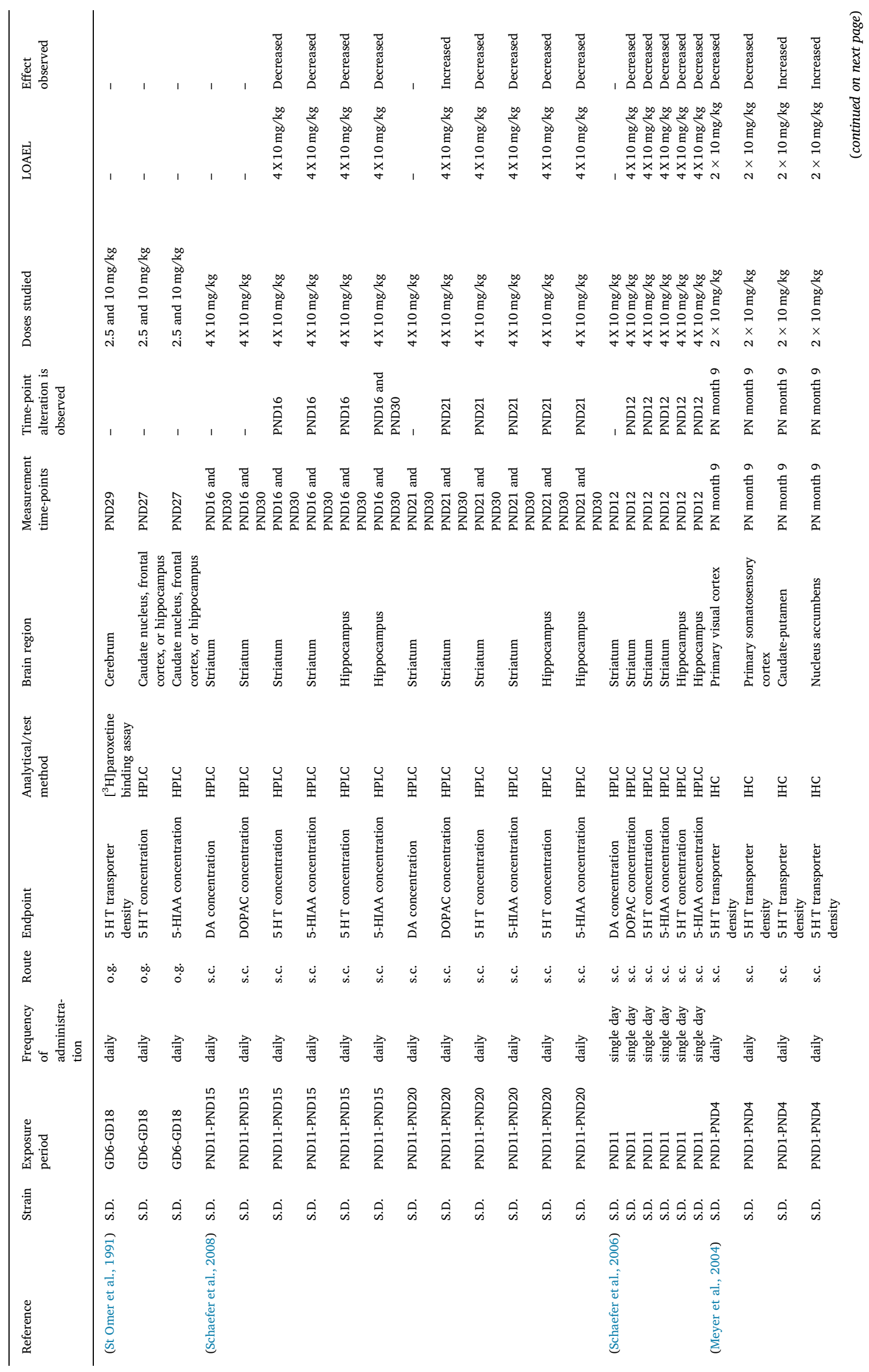




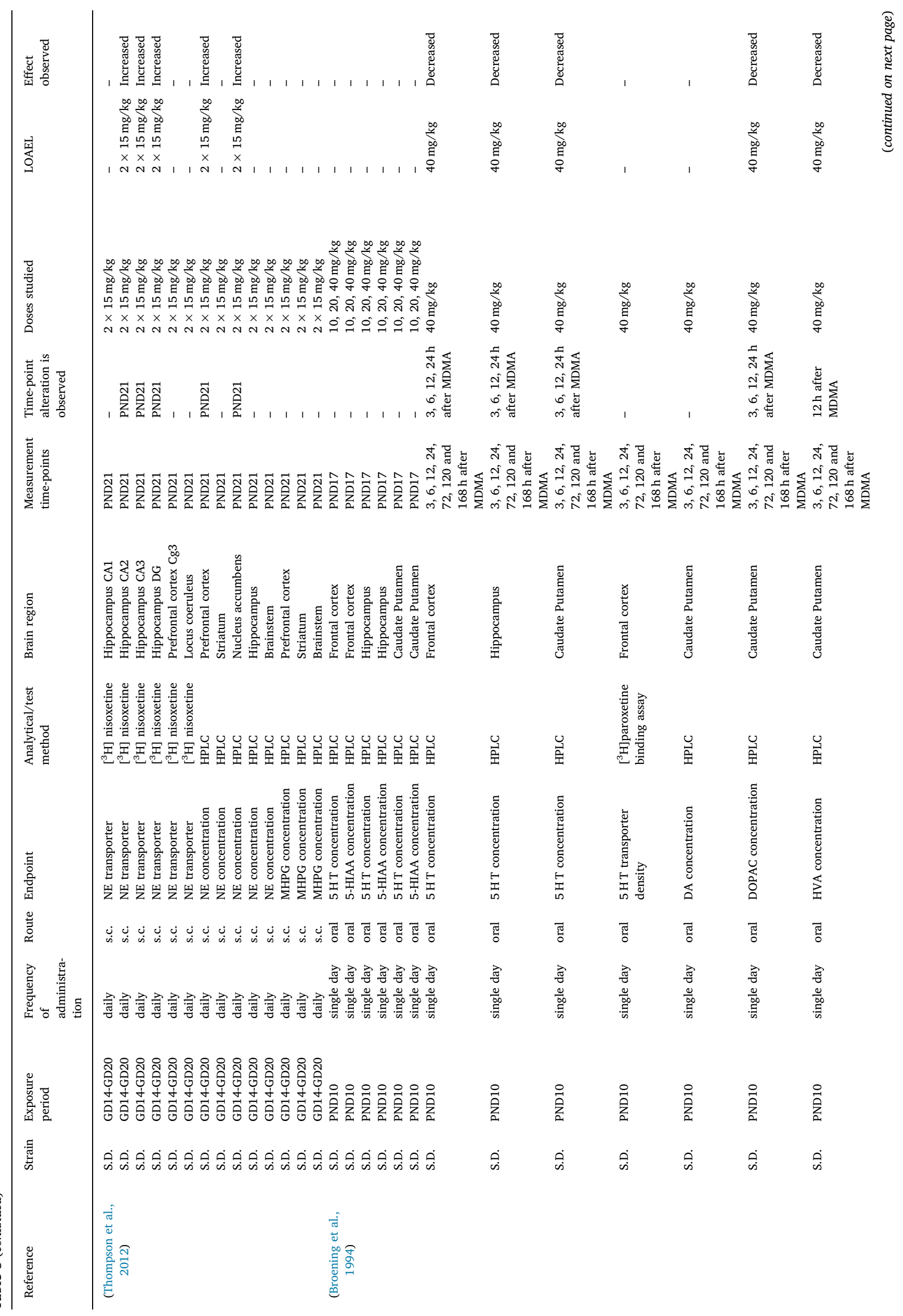




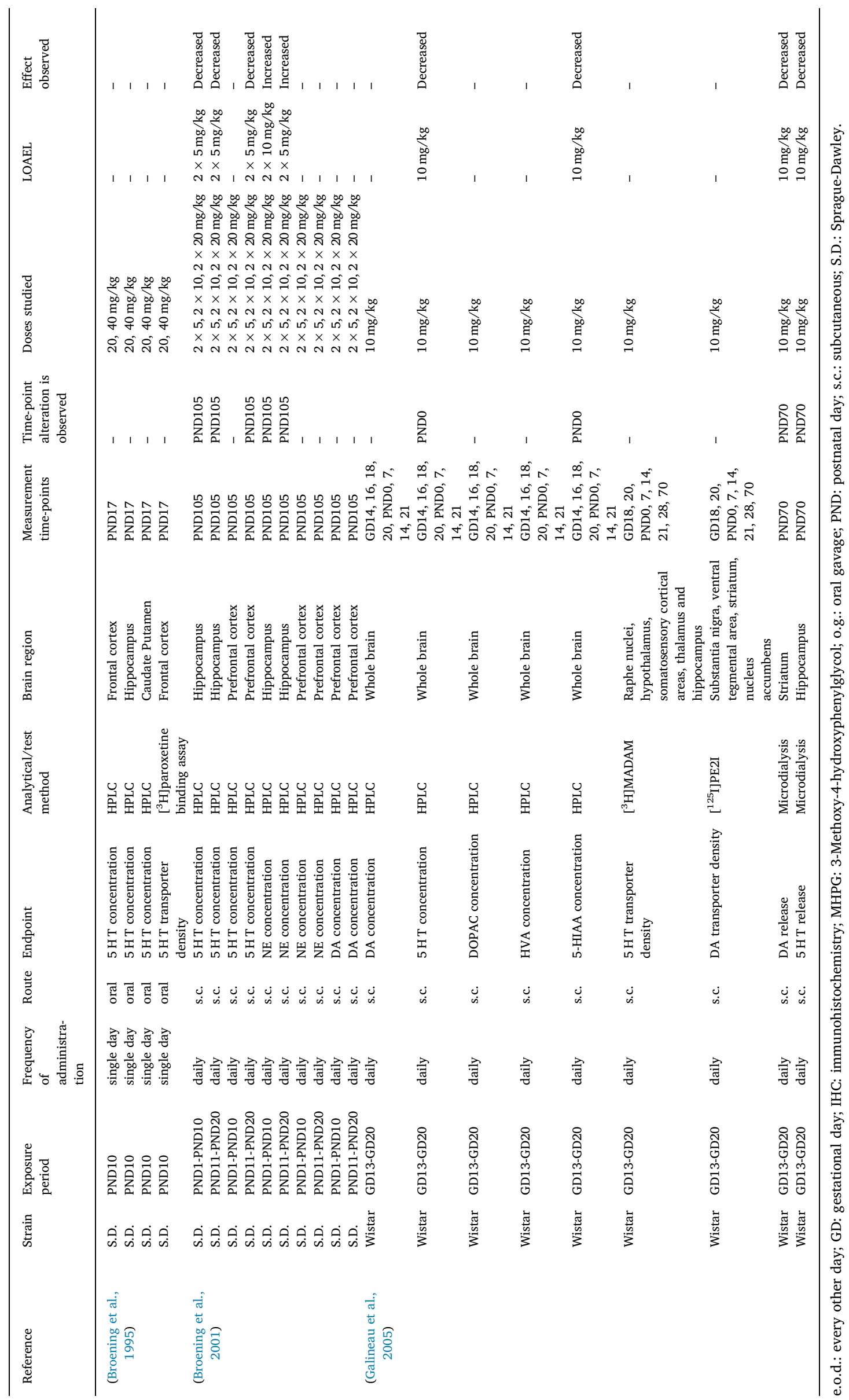



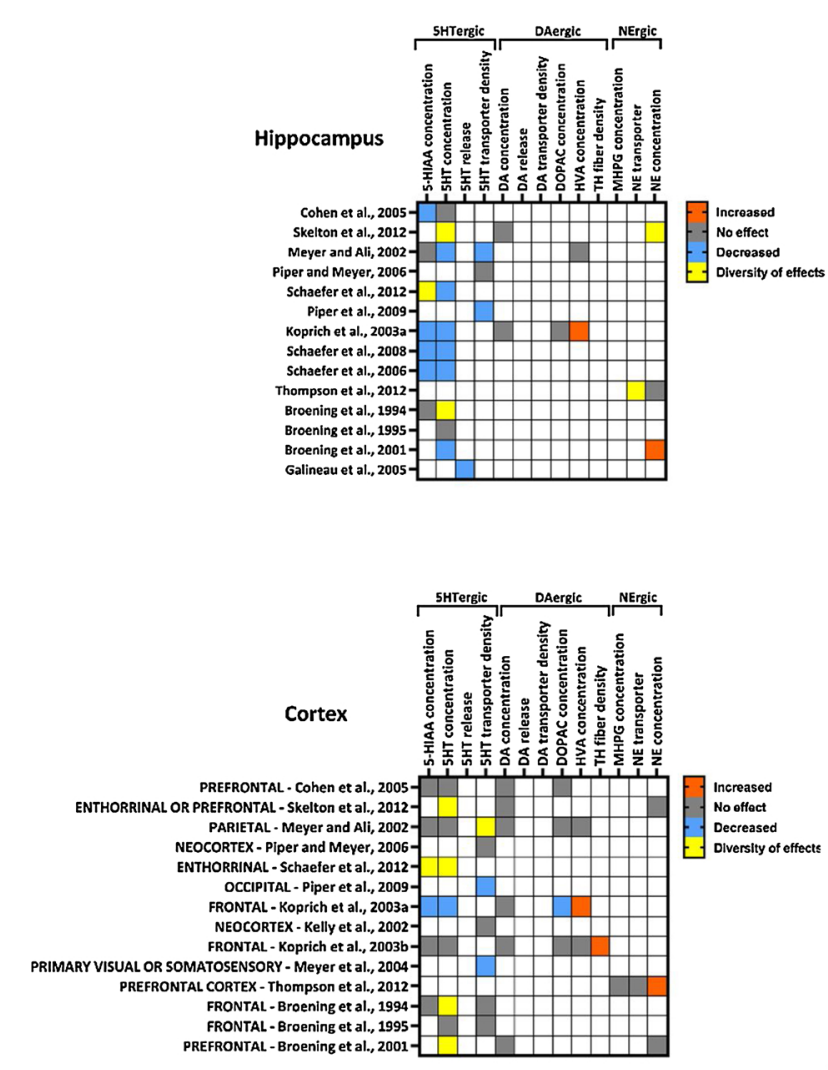

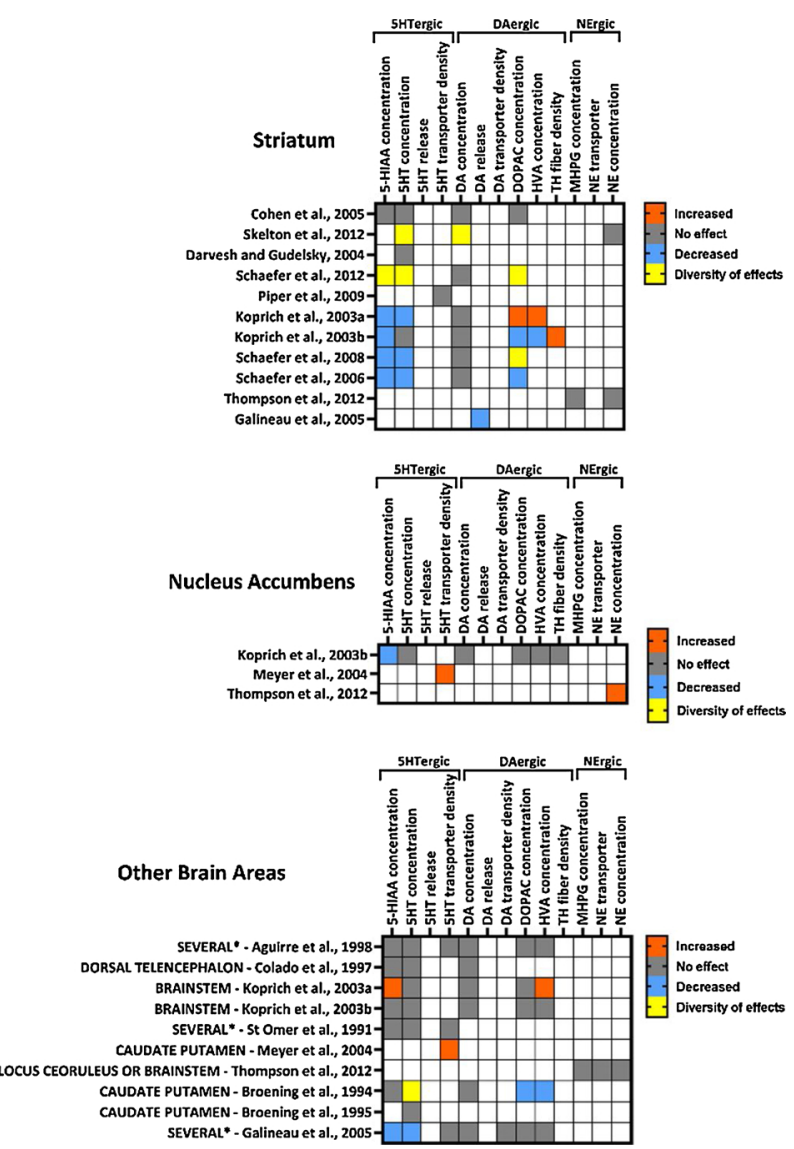

Fig. 3. Heatmap panels summarizing the information about DNT studies of MDMA in vivo in rats evaluating neurotransmission endpoints collected in Table 3. Endpoints measured in a particular study are indicated with colored cells depending on the effect observed (increase - orange, decrease - blue, diverse effects yellow) or the absence of effect (grey). Cortical areas evaluated in the 'Cortex' panel are indicated in capital letters before the reference of each study. For more information about the details of each specific study, and the different brain areas included in the three studies of the panel 'Other Brain Areas' indicated with SEVERAL*, readers are referred to Table 3.

parameters of physical, functional and neuromotor maturation. While Kwack et al. (2014) did not find any adverse effect on physical development nor in motor reflexes, Kaizaki et al. (2014) linked MDMA exposure to delays in acquiring the righting reflex test, cliff-avoidance test and wire hanging maneuver, thus indicating alterations in reflexes and in motor development. However, the dose at which these behavioural adverse effects were observed $(20 \mathrm{mg} / \mathrm{kg}$ b.w.), already produced a significant decrease in survival rate at PND4 and a significant decrease in body weight which makes it difficult to classify the adverse effects as specific DNT effects. The last study performed in mice (Eun et al., 2010) used a similar oral MDMA exposure paradigm, yet with a later onset of treatment (from GD15 to PND21, $20 \mathrm{mg} / \mathrm{kg}$ b.w.). Here, cell degeneration was not assessed because the study evaluated gene expression in the cerebral cortex of male and female offspring at PND77. Altered genes in mice developmentally treated with MDMA were related with 9 common KEGG (Kyoto Encyclopedia of Genes and Genomes) pathways: the MAPK signaling pathway, focal adhesion pathway, insulin signaling pathway, calcium signaling pathway, regulation of actin cytoskeleton,
Wnt pathway, neuroactive ligand-receptor interaction pathway, axon guidance and colorectal cancer signaling. Although the timepoint of gene expression analyses (PND77) was too late to predict a developmental MDMA MoA, similar studies examining earlier timpoints possibly in a species reacting more similar to humans could be the basis for designing in vitro experiments that unravel the MDMA MoA of neurodevelopmental toxicity.

Among the 30 studies performed in rats, the most common strain used was Sprague-Dawley. Only one study was performed in Long Evans and five in Wistar rats. A common limitation of these rat in vivo studies is the low number of dose-response studies that investigate more than two doses. Only five papers include three dose groups of MDMA plus the control to support the evaluation of dose-response relationships (Barenys et al., 2010; Broening et al., 2001, 1994; Dzietko et al., 2010; Vorhees et al., 2009, 2004). However, due to the overall low number of publications on the topic, single or two dose group studies were also considered in this review. Another limitation of most of the animal in vivo studies is the lack or reduced information on MDMA maternal or 


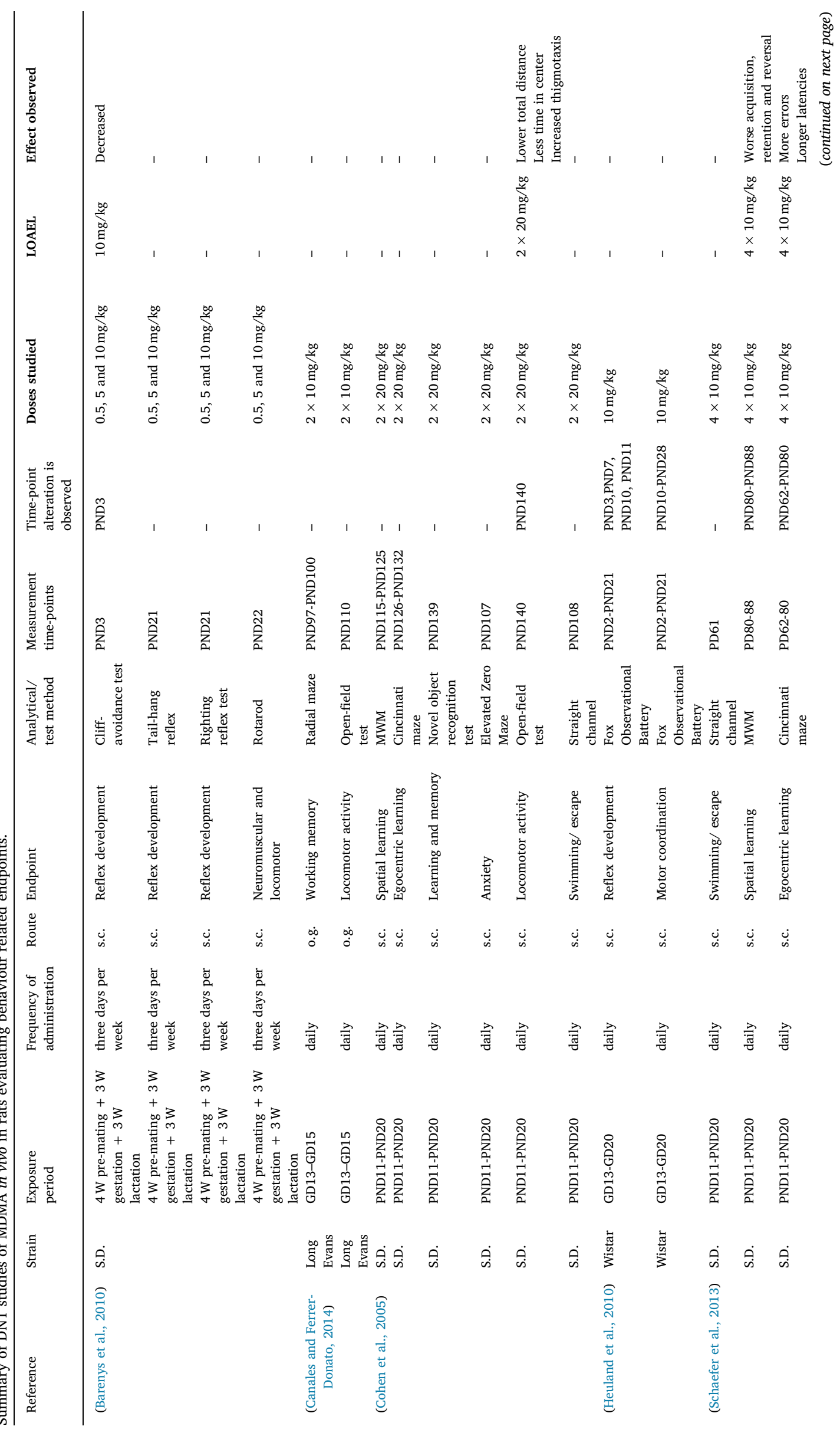




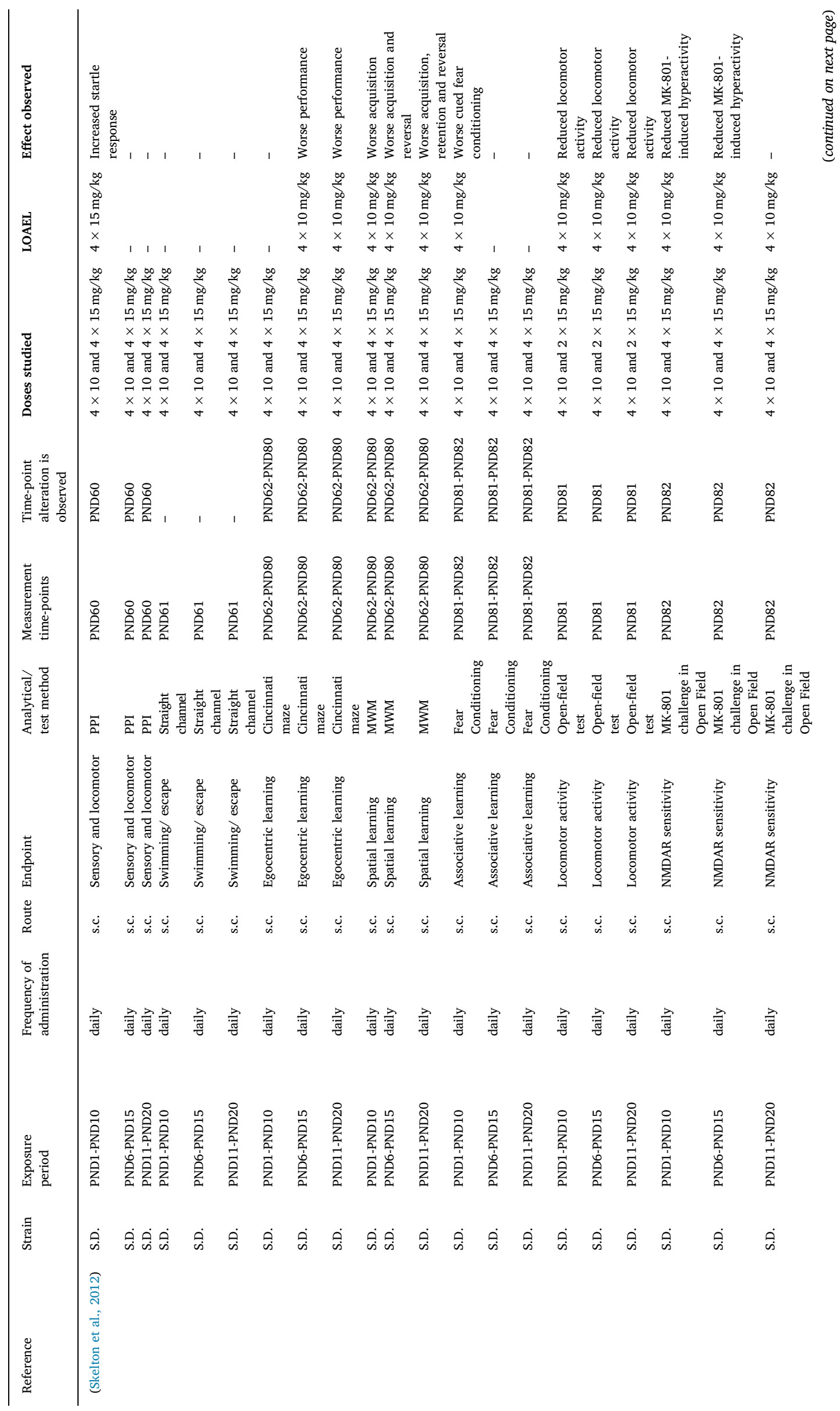




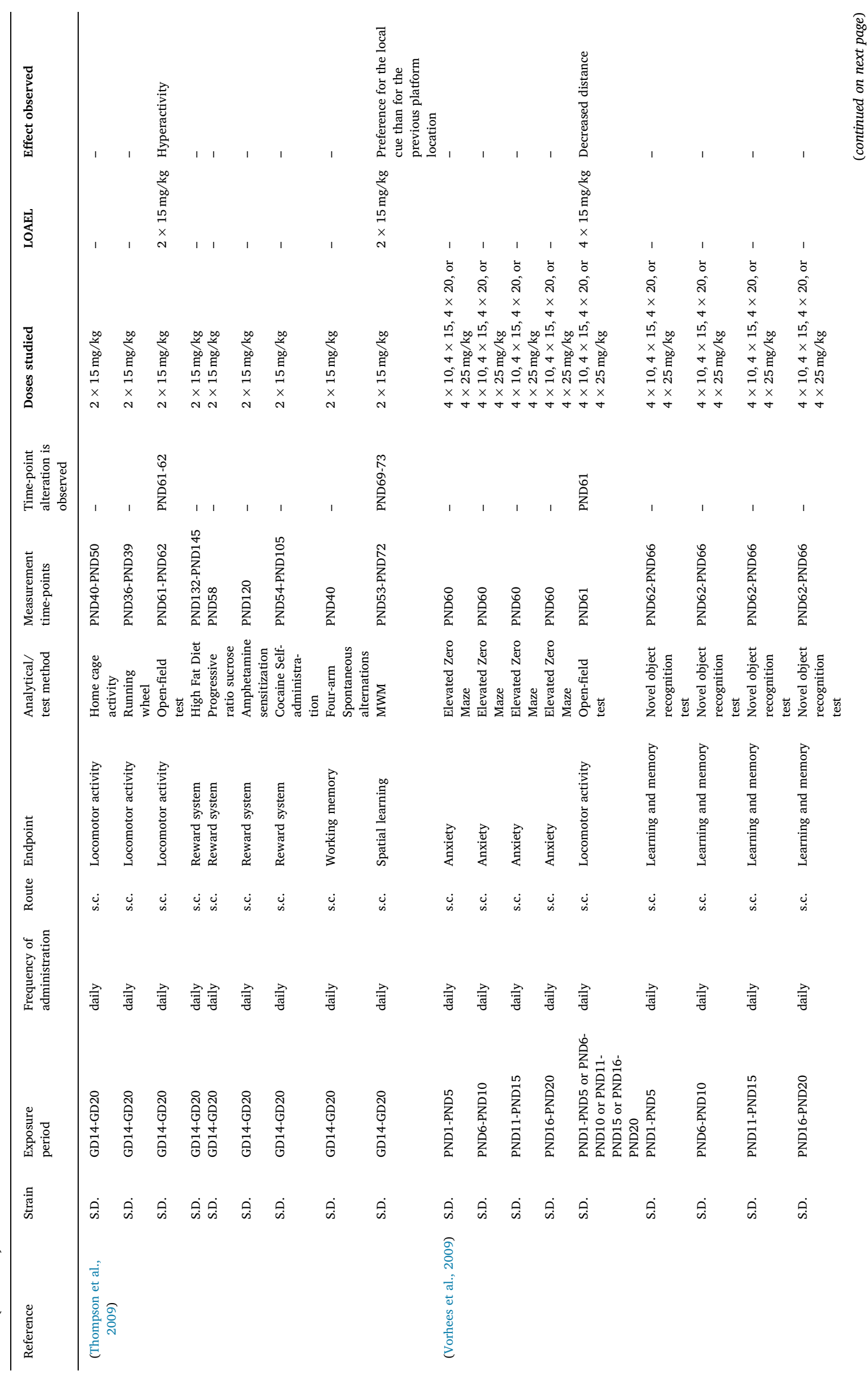




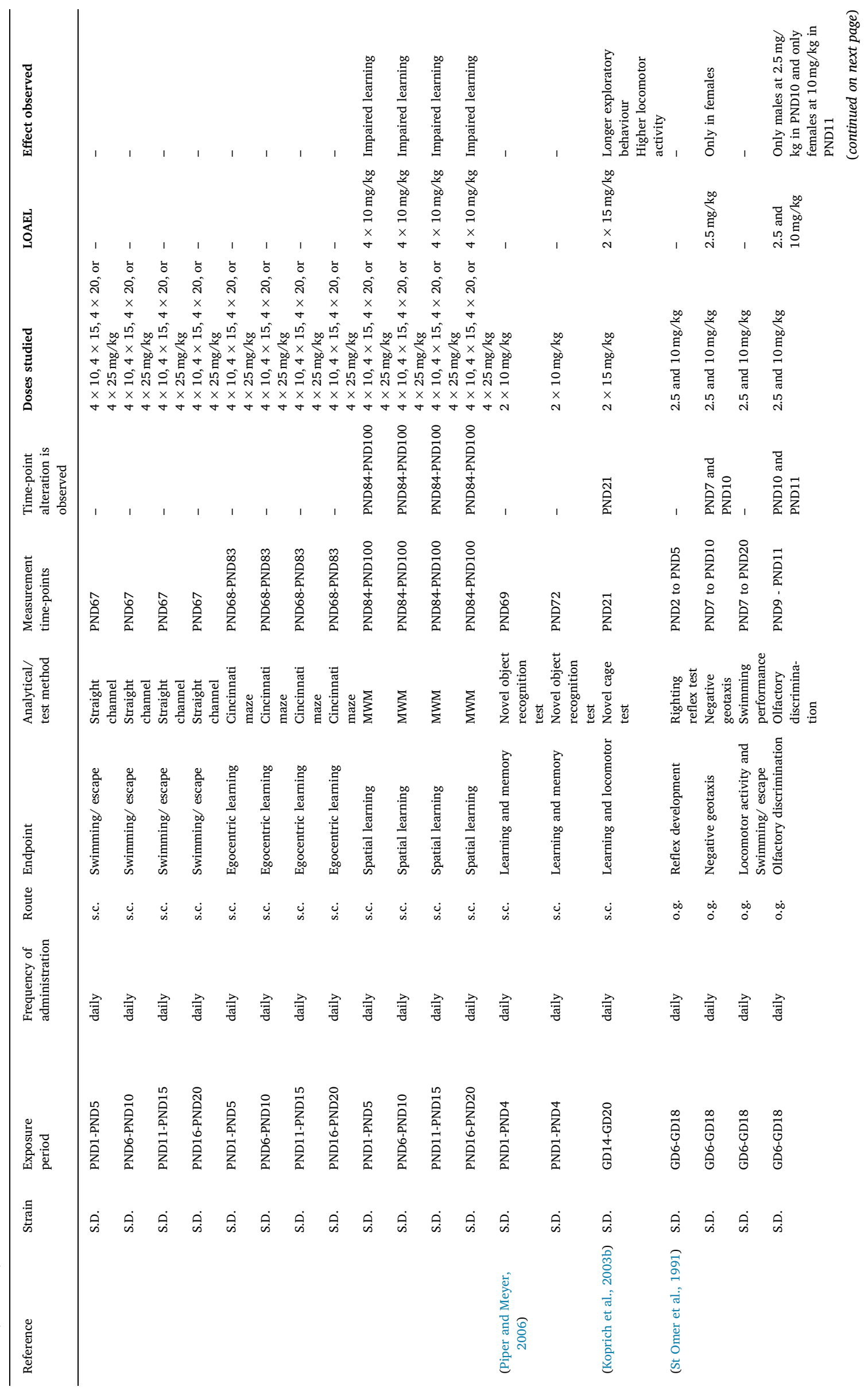




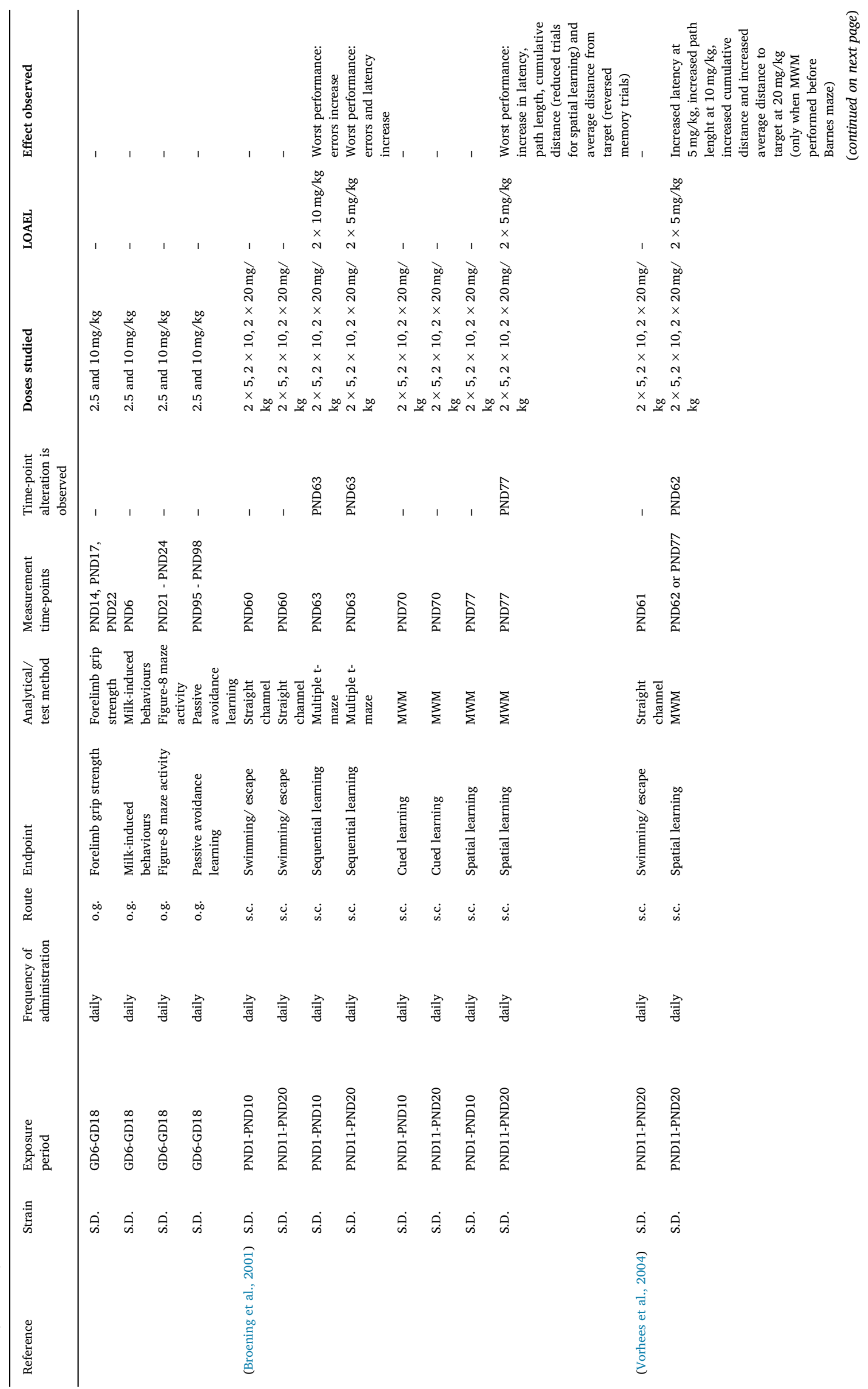


pup general toxicity. This deficiency makes the effect evaluation difficult to distinguish between DNT effects and general/maternal toxicity effects. Despite these limitations, there were common features seen in the rat in vivo studies that in the following paragraphs will be discussed according to five groups of studied endpoints, i.e. neurotransmission, behaviour, general development, effects on growth factors and other endpoints.

\subsubsection{Neurotransmission}

With twenty-one studies evaluating the effects of developmental exposure to MDMA on different neurotransmission related endpoints like concentrations of serotonin (5HT), dopamine (DA) or norepinephrine (NE) and their metabolites or binding to their transporters, this was the most studied group of endpoints among the articles reviewed (see Table 3 and Fig. 3).

Three studies evaluated the effects of MDMA on NEergic neurotransmission, and all of them found a significant increase in NE concentration, either in hippocampus, prefrontal cortex or nucleus accumbens (Broening et al., 2001; Skelton et al., 2012; Thompson et al., 2012). Two of these studies exposed animals postnatally and observed the alteration in the hippocampus but not in other brain areas (Broening et al., 2001; Skelton et al., 2012), while if exposure occurred prenatally the effect was observed in the prefrontal cortex and nucleus accumbens but not in the hippocampus (Thompson et al., 2012). The only study evaluating norepinephrine transporter (NET) binding reported a significant increase also only in the hippocampus, while

the concentration of NE metabolite MHPG (3-Methoxy-4-hydroxyphenylglycol) was not affected according to Thompson et al. (2012). From these in vivo results in rats the question arises if a proposed MoA involving effects of MDMA on the NE system can be related to the adverse outcome (AO) observed in children. An accumulation of NEergic neurons is positioned in the locus coeruleus located in the pons in vivo. Extensive coeruleo-cortical innervation is found to a variety of brain regions including the motor cortex suggesting that NE modulates the activity of these projected brain areas (Counts and Mufson, 2012). Indeed, mice lacking the ability to produce NE by knocking out the dopamine beta-hydroxylase (DBH) gene demonstrate the importance of NE during development and suggest that motor output is likely to be regulated by NE at both the central and peripheral level (Thomas and Palmiter, 1997). However, reduced $\mathrm{NE}$ causes reduced motor functions. In the MDMA treated rats, mainly increasing NE was measured in rat brains raising the question if indeed actions on the NE system are related to the decreased motor functions seen in children prenatally exposed to MDMA as described above. However, the NE system also controls arousal including stress response, attention, and memory function (Counts and Mufson, 2012). The human in vivo study observed a lower MDI early that was not observed at older ages (Singer et al., 2012b). It might be that the human brain has the ability to compensate for a non-functional $\mathrm{NE}$ system during development. This was suggested earlier based on the observation that patients with genetic D $\beta \mathrm{H}$-deficiency show remarkably normal cognitive functions (Jepma et al., 2011). In addition, there is an indication of NE dysregulation in human psychiatrial disease. NE was found hypersecreted in plasma in patients with unipolar depression and generalized anxiety (Sevy et al., 1989; Wyatt et al., 1971). If this dysregulation of the noradrenergic system is cause or consequence of these psychiatric diseases is not clear. However, long-term follow up of prenatally MDMA exposed children for their susceptibility to develop NE-related psychiatrial disorders seems desirable.

Among 13 studies evaluating DA concentration in different brain areas, 12 found no significant effects, including studies performed during pre- or postnatal periods (Aguirre et al., 1998; Broening et al., 2001, 1994; Cohen et al., 2005; Colado et al., 1997; Galineau et al., 2005; Koprich et al., 2003a, 2003b; Meyer and Ali, 2002; Schaefer 


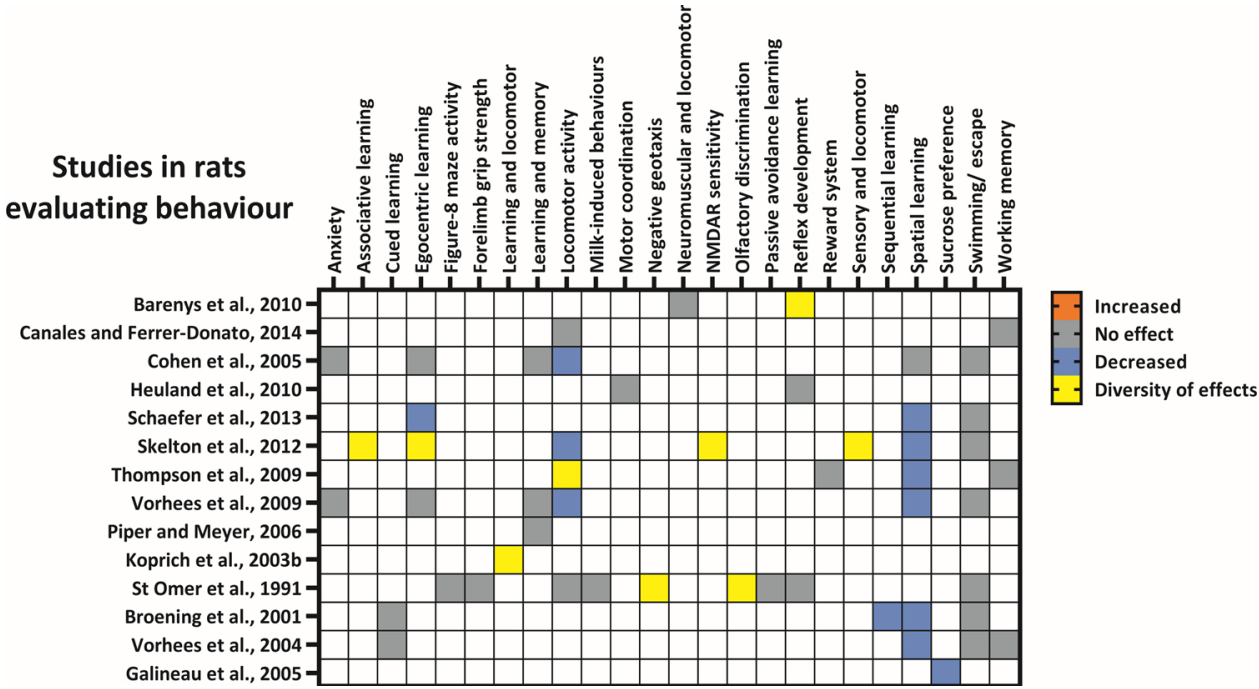

Fig. 4. Heatmap summarizing the information about DNT studies of MDMA in vivo in rats evaluating behavior related endpoints collected in Table 4. Endpoints measured in a particular study are indicated with colored cells depending on the effect observed (increase - orange, decrease - blue, diverse effects - yellow) or the absence of effect (grey). For more information about the details of each specific study, readers are referred to Table 4. et al., 2008, 2006, 2012; Skelton et al., 2012). Only one study evaluated DA transporter binding and also detected no significant effects (Galineau et al., 2005). Concerning the effects of MDMA on concentrations of DA metabolites in specific brain areas, the results of ten studies were inconsistent. MDMA affected 3,4-dihydroxyphenylacetic acid (DOPAC) concentrations only at higher doses (administering $40 \mathrm{mg} / \mathrm{kg}$ b.w., $4 \times 10 \mathrm{mg} / \mathrm{kg}$ b.w., $2 \times 20 \mathrm{mg} / \mathrm{kg}$ b.w. or $2 \times 15 \mathrm{mg} /$ kg b.w.) (Broening et al., 1994; Koprich et al., 2003a, 2003b, Schaefer et al., 2012, 2008, 2006), while studies administering lower doses ( $10 \mathrm{mg} / \mathrm{kg}$ b.w., $2 \times 10 \mathrm{mg} / \mathrm{kg}$ b.w. or $20 \mathrm{mg} / \mathrm{kg}$ b.w) caused no significant changes in DOPAC concentrations, independently of the administration period (pre- or postnatal) and length (1-10 days) (Aguirre et al., 1998; Cohen et al., 2005; Galineau et al., 2005; Meyer and Ali, 2002). For the positive studies, however, changes were not uniform. While some studies observed an increase in DOPAC concentration others measured decreases. Similarly, MDMA also affected another metabolite of DA, homovanillic acid (HVA). Three articles studying lower MDMA doses $(10 \mathrm{mg} / \mathrm{kg}$ b.w., $2 \times 10 \mathrm{mg} / \mathrm{kg}$ b.w. or $20 \mathrm{mg} / \mathrm{kg}$ b.w.) detected no significant changes in HVA (Aguirre et al., 1998; Galineau et al., 2005; Meyer and Ali, 2002) while three articles including higher MDMA doses $(40 \mathrm{mg} / \mathrm{kg}$ b.w., $2 \times 20 \mathrm{mg} / \mathrm{kg}$ b.w. or $2 \times 15 \mathrm{mg} / \mathrm{kg}$ b.w.) found significantly changed HVA concentrations in both directions, increased and decreased (Broening et al., 1994; Koprich et al., 2003a, 2003b). The reason for these inconsistent results on DA metabolite changes after MDMA exposure is not clear. As far as we can tell, there is not enough information to rule out that exposure scheme, timing or route of exposure or brain regions are related to the unequal effects of MDMA on DOPAC or HVA concentrations in rat brains. Nevertheless, we again ask the question if a proposed MoA involving effects of MDMA on the DAergic system can be related to the $\mathrm{AO}$ of decreased motor activity observed in children. Dopaminergic structures express connecting fibres to many different parts of the brain playing essential roles in aspects as simple as motivating basic movement and complex as cognition (Bissonette and Roesch, 2016). Moreover, DA is one of the earliest neurotransmitters occuring in the developing brain significantly shaping neuronal cytoarchitecture and circuitry by modulating cell proliferation, migration, and differentiation. Modifying DA receptor signaling during development alters amongst others tangential migration of GABAergic neurons possibly resulting in inappropriate neuronal excitation-inhibition balance in cortex. In addition, it modulates dendritic growth and the formation of dendritic spines, which, in the hyperdopaminergic DA transporter knockout mouse leads to the behavioural phenotype of hyperactivity (comprehensively reviewed in Money and Stanwood, 2013). Hence, developmental interference with the DA system is a possible MoA of MDMA causing behavioural abnormalities in children. Because dysregulation of the DAergic system also plays a fundamental role in neuropsychiatric disease later in life, follow-up studies of the children prenatally exposed towards MDMA in combination with human in vitro studies would shed more light on the mechanisms and consequences this exposure has in humans.

Finally, the most studied neurotransmitter in MDMA DNT studies was $5 \mathrm{HT}$, with 16 articles evaluating its concentrations at different times after MDMA developmental exposure (Aguirre et al., 1998; Broening et al., 2001, 1995, 1994; Cohen et al., 2005; Colado et al., 1997; Darvesh and Gudelsky, 2004; Galineau et al., 2005; Koprich et al., 2003a, 2003b; Meyer and Ali, 2002; Schaefer et al., 2012, 2008, 2006; Skelton et al., 2012; St Omer et al., 1991). Among these studies only 8 found adverse effects of MDMA on 5HT concentrations in different brain areas. However, if the brain area studied is restricted to the hippocampus, 8 out of 10 articles detected a significant decrease in 5HT concentration, while in other brain regions results were less homogeneous. Concentrations of the 5HT metabolite 5Hydroxyindoleacetic acid (5-HIAA) were evaluated in 12 studies, among which 7 detected an adverse effect, with a very similar pattern than $5 \mathrm{HT}$ concentration alterations. If the brain region again is restricted to hippocampus, 5 out of 7 studies detected a significant decrease, and in this case, 5 out of 6 studies also reported a significant decrease in the concentration of the metabolite in the striatum. Ten studies evaluated effects on serotonin transporter binding. Surprisingly, adverse effects were detected only in three out of the four experiments administering MDMA from PND1 to PND4 and earlier or later exposures did not find adverse effects in this endpoint. Similar to 
DA, 5HT plays two key roles during development: during early development it acts as a growth factor by regulating cell division, differentiation, migration, myelination, synaptogenesis, and dendritic pruning before taking on its second role as a neurotransmitter in the mature brain regulating sensory and motor function, cognition, attention, emotion, pain, sleep and arousal (reviewed in Brummelte et al., 2017; Shah et al., 2018). 5HT is also central to the development and function of two key stress response systems - the hypothalamicpituitary-adrenal and the locus-coeruleus-NE systems that shape self-regulation and mental health across the lifespan and was already discussed above (reviewed in Brummelte et al., 2017; Shah et al., 2018). From these functions two scenarios for how alteration of the 5HT system by MDMA can lead to the observed neurobehavioural effects in children can be envisioned. First, through a direct effect of MDMA on the serotoninergic system or secondly by indirectly interfering with the proper development of the locus coeruleus-NE system. Interestingly, the postnatal phase in rats is the most sensitive when it comes to MDMA interfering with serotonin transporter binding, as postnatal depletion of serotonin in rat pups via treatment with pchlorophenylalanine (PCPA) leads to locomotor deficits (Vinay et al., 2005). MRI analyses in serotonin transporter Slc6a4 knockout mice clearly shows that despite the small number of 5HT neurons and their localization to the brainstem, 5HT plays an important role in neuroanatomical organization (Ellegood et al., 2018). In terms of development of the serotonergic system the first postnatal weeks in rodents correspond to the 3rd trimester of pregnancy in humans (Suri et al., 2015).

Despite the multitude of studies describing effects of MDMA on neurotransmitter concentrations in developing brains, the precise MoA underlying the DNT of MDMA is still mysterious.

\subsubsection{Behavioural endpoints}

The second most studied group of endpoints following MDMA exposure was behaviour, evaluated in fourteen articles summarized in Table 4 and Fig. 4 (Barenys et al., 2010; Broening et al., 2001; Canales and Ferrer-Donato, 2014; Cohen et al., 2005; Galineau et al., 2005; Heuland et al., 2010; Koprich et al., 2003b; Piper and Meyer, 2006; Schaefer et al., 2013; Skelton et al., 2012; St Omer et al., 1991; Thompson et al., 2009; Vorhees et al., 2009, 2004). Here, locomotor behaviour was studied after pre- or postnatal MDMA exposure. Interestingly, time of exposure is crucial for the adverse outcome: exposure during gestation either causes no adverse effects in locomotion or significant hyperactivity (Canales and Ferrer-Donato, 2014; Koprich et al., 2003b; St Omer et al., 1991; Thompson et al., 2009). In contrast, direct postnatal MDMA administration causes hypoactivity (Cohen et al., 2005; Skelton et al., 2012; Vorhees et al., 2009), independently of when during the postnatal period up to PND20 the exposure takes place. Therefore, among all exposure schemes reviewed, postnatal exposure towards MDMA produces the most similar effects in rat compared to human behaviour described in Section 3.1. One major issue of pre- and postnatal exposure in rats compared to humans is the pre- and postnatal exposure routes. During gestation, in analogy to humans, the rat fetus is exposed to the test substance by transplacental transfer from the dam. However, postnatally rat pups' chemical exposure happens through breast milk or in most of the reviewed studies by direct subcutaneous administration. In contrast, during the corresponding rat postnatal phase humans are still developing in utero (Clancy et al., 2007, 2001) and thus exposed through the placental route. This can lead to different exposure doses of parent compounds and/or their metabolites between the species (Tsuji and Crofton, 2012). If these kinetic issues, translating neurodevelopmental time differences and/or species differences are part of the reason why pre- and postnatal MDMA exposure causes such opposite effects only in rat offspring, yet not in children is currently enigmatic.

Other behaviours commonly tested in a neurobehavioural testing battery are for example swimming/escape ability or spatial learning. No adverse effects were detected in any of the seven studies evaluating swimming/escape ability which included different pre- and postnatal exposure schemes (Broening et al., 2001; Cohen et al., 2005; Schaefer et al., 2013; Skelton et al., 2012; St Omer et al., 1991; Vorhees et al., 2009, 2004). These results reflect an equal performance in swimming and motivation in MDMA treated pups than in controls and are helpful to interpret results of other behavioural tests requiring swimming skills and motivation to escape. Such a commonly used behavioural test that combines swimming and motivation to escape with spatial learning skills is the Morris Water Maze (MWM). Drugs increasing serotonergic stimulation, like selective serotonin reuptake inhibitors, can have a positive influence on motivation and swimming behaviour in adult rats and thus modulate the performance in the MWM (Bogdanova et al., 2013). However, six out of seven articles found that MDMA impaired spatial learning in the MWM independent of altered swimming and motivation behaviour, which in most cases depended on the exposure period, being the latest postnatal period (PND10 to PND20) the most sensitive one (Broening et al., 2001; Schaefer et al., 2013; Skelton et al., 2012; Thompson et al., 2009; Vorhees et al., 2009, 2004). MDMA developmental exposure decreases serotonin content in the hippocampus (see Neurotransmission endpoints), yet other studies evaluating the effects of drugs producing depletion of serotonin, like PCPA, did not detect alterations in these behaviours in adult animals (Page et al., 1999). As neurotransmitters have trophic functions early during development which are clearly distinct from synaptic signal transmission, adult neurotoxicity studies might not be representative for developmental exposure in their outcomes. Brain regions implied in MWM navigation include the striatum (Whishaw et al., 1987), prefrontal cortex (Mogensen et al., 1995), and especially the hippocampus (Morris et al., 1982), the latter being the brain region where most consistent effects of developmental MDMA exposure on neurotransmitter, especially 5HT concentrations were measured. Serotonergic lesions have already been related to severe spatial learning deficits in rats (Richter-Levin et al., 1994), which can be reduced by restoring the serotonergic innervation of the hippocampus by raphe grafts (RichterLevin et al., 1994). If indeed MDMA acts via the serotonergic system on rat behavior, i.e. spatial memory, and if there is any relevance of this behavioural change for humans needs further investigations.

For all other behavioural tests studies were sparse and their results contradictory. Therefore, they could not be sufficiently evaluated within this review.

\subsubsection{General developmental landmarks}

Two of the studies analyzed included the evaluation of MDMA effects on general developmental landmarks (Table 5), as eye opening or incisor eruption (Heuland et al., 2010; St Omer et al., 1991). The inclusion of these parameters is valuable as it helps to discern between general developmental delay and specific neurodevelopmental 
effects. Yet within the two studies including general developmental landmarks, opposite results were produced. While one study reported delayed eye opening and incisor eruption (Heuland et al., 2010) the second one did not find any of these developmental delays (St Omer et al., 1991). Exposure period in the positive study was shorter than the negative study and contained the same time frame. Moreover, the studies shared the maximum dose of MDMA ( $10 \mathrm{mg} / \mathrm{kg}$ b.w.). One explanation of the differences in result could be the rat strain used; general development of the Sprague-Dawley rat was unaffected by MDMA, while Wistar rat pups showed the developmental delay. Although these results are not conclusive, inclusion of such general developmental endpoints in neurodevelopmental studies is advisable.

\subsubsection{Effects on growth factors}

Out of the 30 studies in rats only 4 evaluated the effects of postnatal MDMA exposure on growth factor signaling (Dzietko et al., 2010; Koprich et al., 2003a; Piper et al., 2009; Schaefer et al., 2012). Growth factors studied were nerve growth factor (NGF), neurotrophin-3 (NT-3), and brain-derived neurotrophic factor (BDNF; see Table 6). None of the studies found alterations in NGF concentration or gene expression, while the only one evaluating effects in NT-3 detected a significant increase in its gene expression (Dzietko et al., 2010). All four studies included the evaluation of BDNF, but only two observed a significant increase in its gene or protein expression (Dzietko et al., 2010; Koprich et al., 2003a). In this case a general conclusion cannot be drawn from the data because exposure timing, strain and brain regions were all different in the studies.

\subsubsection{Other endpoints}

Among other endpoints tested (Table 7) it is worth mentioning two studies evaluating cell death and two more evaluating the effects of MDMA on neurite length and number of neurites per neuron. Cell death was detected in both studies after doses of $60 \mathrm{mg} / \mathrm{kg}$, $3 \times 20 \mathrm{mg} / \mathrm{kg}$ or $2 \times 10 \mathrm{mg} / \mathrm{kg}$ (Dzietko et al., 2010; Meyer et al., 2004), especially after early postnatal exposure (until PND6), but not after later exposure (PND13 or PND20). Adverse effects in neurite length and number of neurites per neuron were also detected in both studies (Thompson et al., 2012; Williams et al., 2014) but not in all areas analyzed. One of these studies included prenatal exposure to $2 \times 15 \mathrm{mg} / \mathrm{kg}$ of MDMA while the other one included postnatal exposure to $2 \times 20 \mathrm{mg} / \mathrm{kg}$, so these results seem independent of the exposure period. During rodent late gestation, neurite outgrowth is modulated by DA (Money and Stanwood, 2013). Hence, a disturbance of the DAergic system by MDMA that is involved in neurite outgrowth may occur but has to be substantiated by experimental evidence.

\subsection{In vitro studies on neurodevelopmental effects of MDMA}

Based on title and abstract screening according to the predefined criteria (see 2.2) 15 publications were selected from the in vitro studies for full text screening. During the full-text reading and acquisition of data 13 articles were excluded because of the following reasons: one did not include MDMA exposure, one was performed in chicken (see exclusion criteria), three obtained category 3 in ToxRTool (not reliable), and eight did not evaluate neurodevelopmental endpoints. Among the latter, two studies by Keating and colleagues were excluded, however, the authors demonstrated that MDMA affects folic acid uptake by human cytotrophoblasts and might thereby indirectly affect folic aciddependent processes during brain development (Keating et al., 2009, 2007).

From the two publications that were selected based on the full text screen (Table 8), one publication used rat mesencephalic neuronal cultures from embryonic day four (E4), which were treated for $96 \mathrm{~h}$ with MDMA starting from day in vitro (DIV) 0 (Lipton et al., 2008). The 


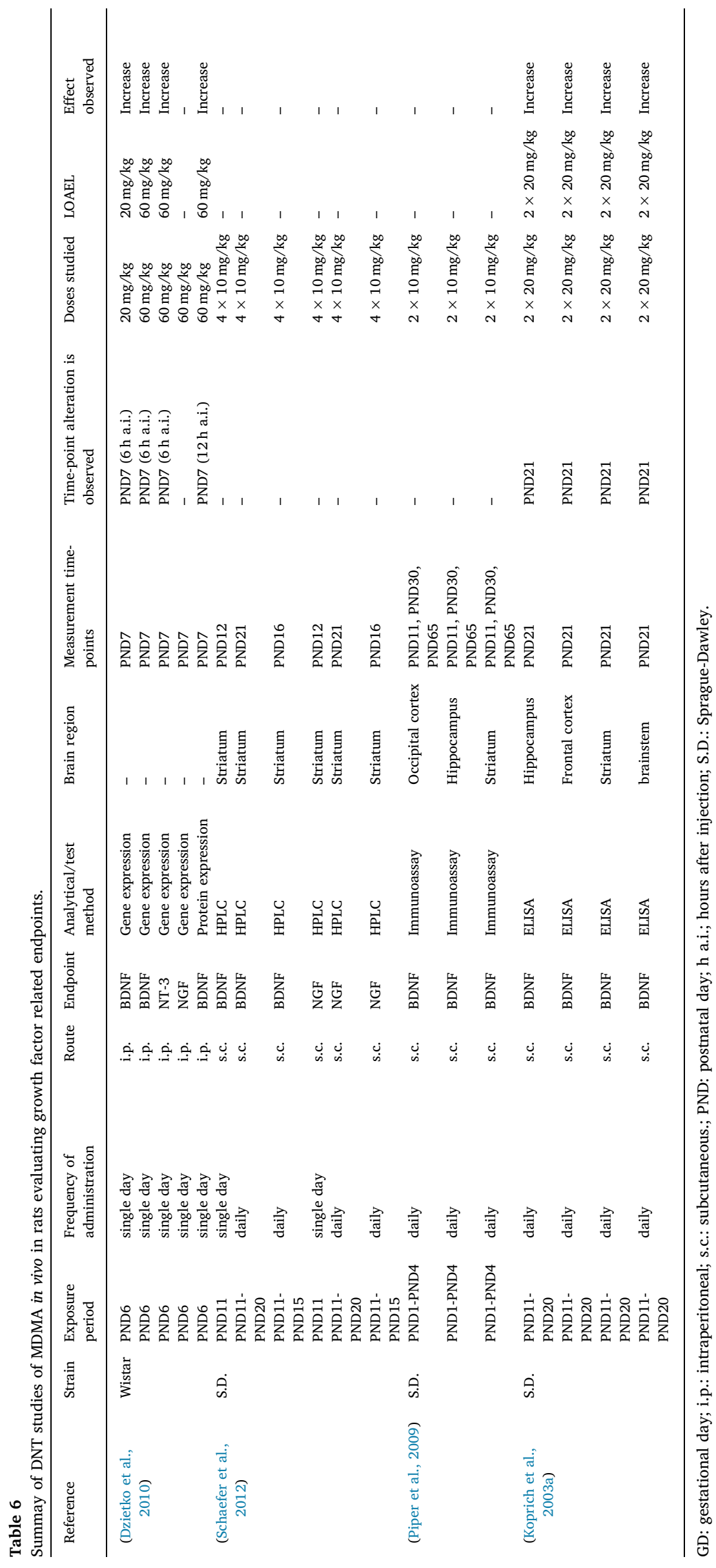




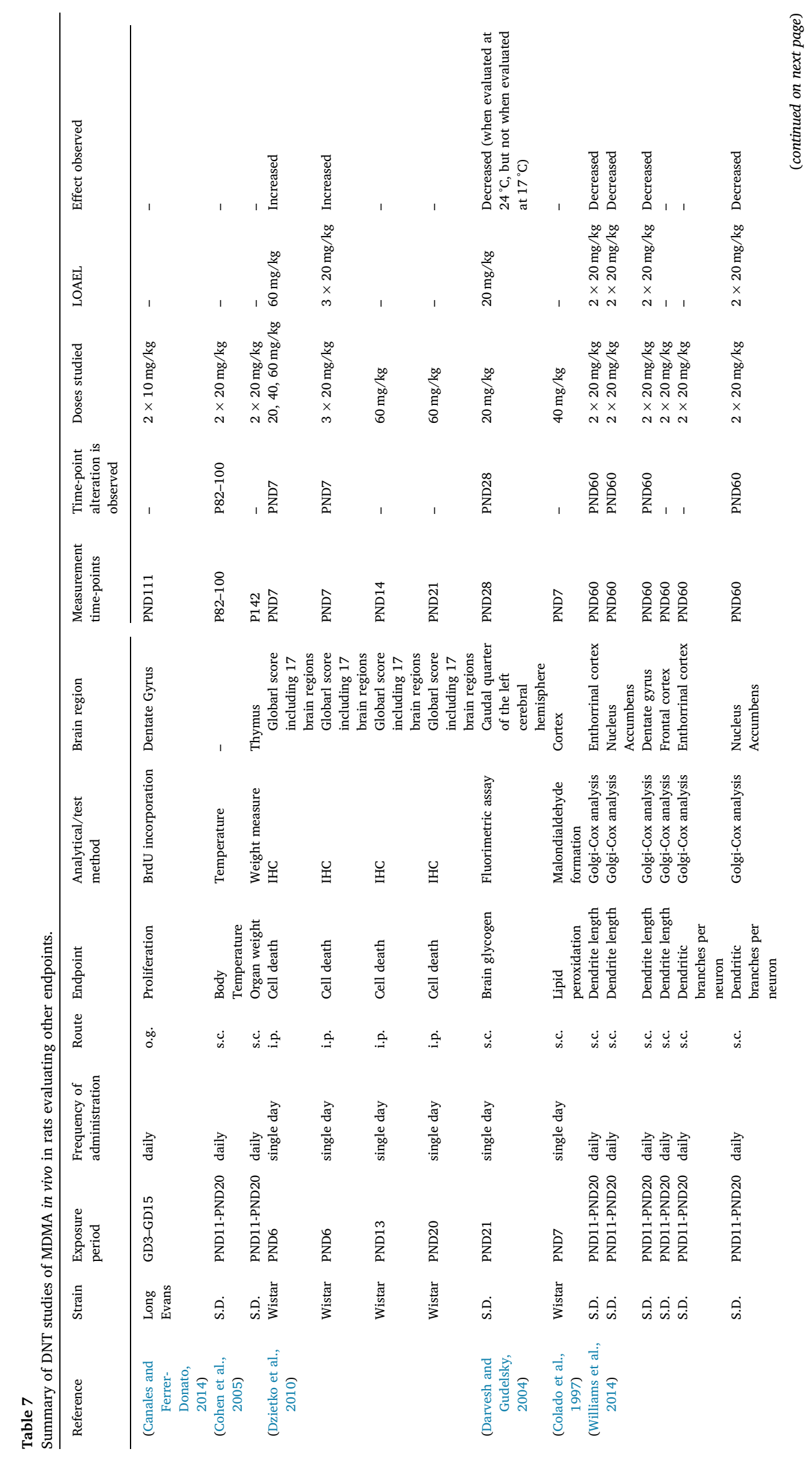




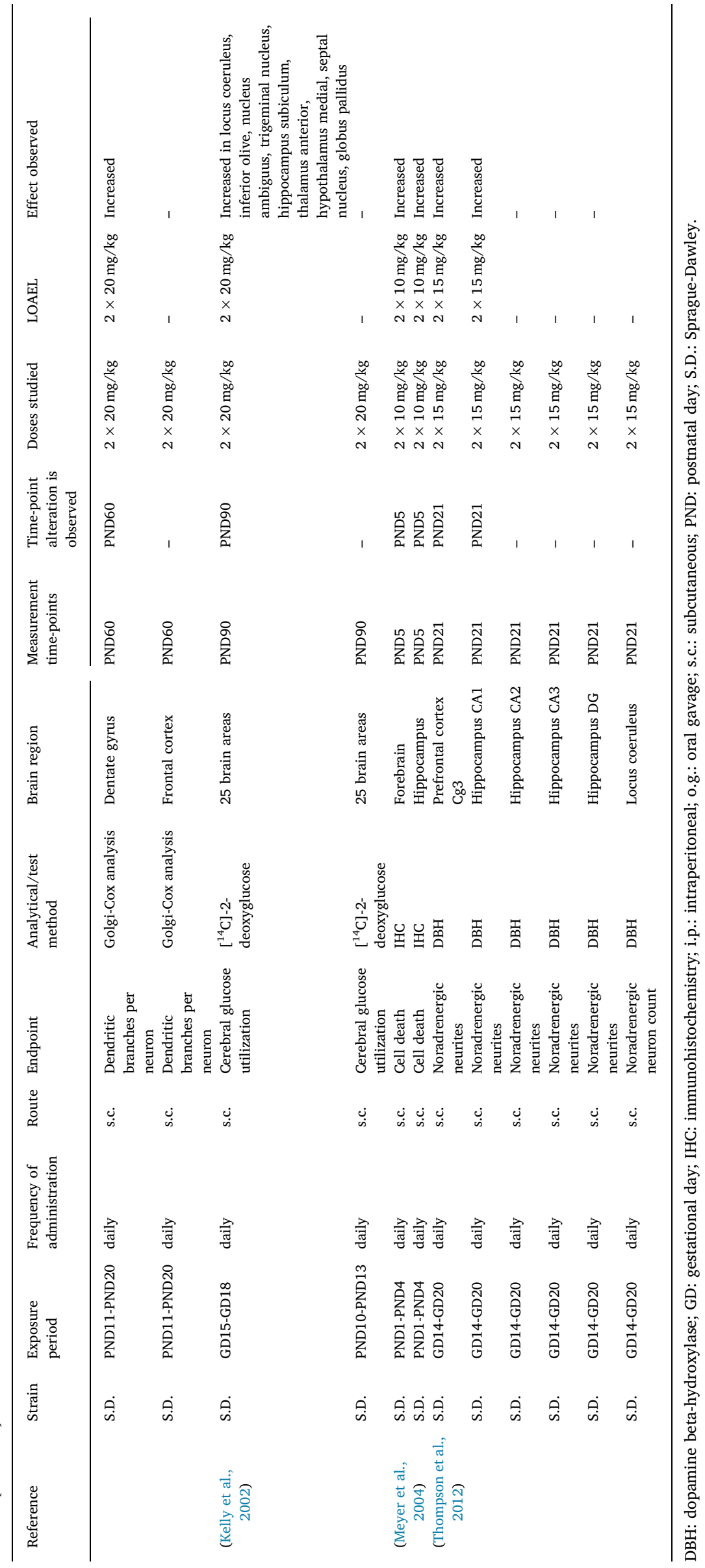


second one employed mouse embryonic stem cells (mESC, Royan B1) and treated them for 10 days during embryoid body formation (Meamar et al., 2010). Experimental cell models, species and endpoints were completely different between the two studies. This is the reason why they are discussed separately here. In rat mesencephalic neuronal cultures MDMA (LOAEC $0.75 \mu \mathrm{M}$ ) increased the number of $\mathrm{TH}^{+}$cells. This effect was stronger when MDMA was administered early, i.e. from 0 to 2 DIV with no exposure from 2 to 4 DIV, compared to late exposure, i.e. no MDMA between 0 and 2 DIV and exposure from 2 DIV to 4 DIV. In two in vivo studies, MDMA increased the number of $\mathrm{TH}^{+}$neurons on PND35 in the substantia nigra of prenatally (GD14-GD20) MDMA exposed rats (Lipton et al., 2008) as well as on PND21 (Koprich et al., 2003b). One of the earliest effects of DA in the developing brain is cell cycle regulation of specific neural progenitor cells. DA causes D1 receptor-dependent cell cycle inhibition with reduction of proliferation of a neural progenitor cells pool that is the source for most striatal neurons (Money and Stanwood, 2013).

The second in vitro study used embroid bodies, which were produced from mESC and subsequently differentiated towards the neural lineage due to retinoic acid treatment. MDMA exposure during the whole differentiation period (10 DIV) decreased neurite outgrowth $\left(\mathrm{IC}_{50} 50 \mu \mathrm{M}\right)$ and MAP2 gene expression (LOAEC $=10 \mu \mathrm{M}$; Meamar et al., 2010). Shorter dendrites after postnatal MDMA exposure were also found at PND60 in rats in the nucleus accumbens, the dentate gyrus and the entorhinal cortex (Williams et al., 2014) indicating that neuronal cytoarchitectural changes induced by MDMA developmental exposure are long-lasting in vivo. Moreover, these cytoarchitectural changes appear in regions consistent with the spatial learning deficits described in the in vivo section (Williams et al., 2014). Neurite outgrowth can be affected by a variety of MoA, one being interference with the DAergic system (Money and Stanwood, 2013). As the in vitro study (Meamar et al., 2010) did not investigate the MoA of MDMA inhibiting neurite outgrowth, more data is clearly needed to unravel the molecular mechanism underlying MDMA DNT.

\subsection{Generation of hypothetical AOPs from collected data}

This review collected available data on the adverse effects of the recreational drug MDMA on the brain during development. The outcomes of human and rodent in vivo as well as rodent in vitro studies were collected, discussed, and subsequently assembled in hypothetical AOPs (Fig. 5). For general introduction to the AOP conceptual framework and specific vocabulary (MIE: molecular initiating event, KE: key event, KER: key event relationship and AO), the reader is referred to the following publications: (Ankley et al., 2010; Bal-Price et al., 2017). The anchors of the hypothetical AOPs are the human AO, which is decreased motor function in children. In rodents in vivo, hypoactivity is observed in offspring when treated with MDMA postnatally. This AO in animals is closest to the human AO observed in the one epidemiological study. Based on the suggested early KE derived from the in vitro studies, we here suggest two hypothetical AOPs.

The first one (Fig. 5) is based on the observation that the model compound for this AOP, MDMA, is transported to the cytoplasm by serotonin transporters competing with 5HT uptake and inducing back-transport of 5HT out of the cell (Hasenhuetl et al., 2018). This mechanism produces first an increase in extracellular 5HT but finally leads to a depletion of $5 \mathrm{HT}$ as a result of a combined effect in other targets like inhibition of tryptophan hydroxylase, the rate-limiting enzyme for 5HT synthesis (Capela et al., 2009). These effects are described in adult brains (Capela et al., 2009), but experimental results reviewed in this article suggest that this 5HT depletion also takes place during neurodevelopment specially after neonatal exposure to MDMA and in particular the hippocampus. Depletion of serotonin concentrations during development by the model 


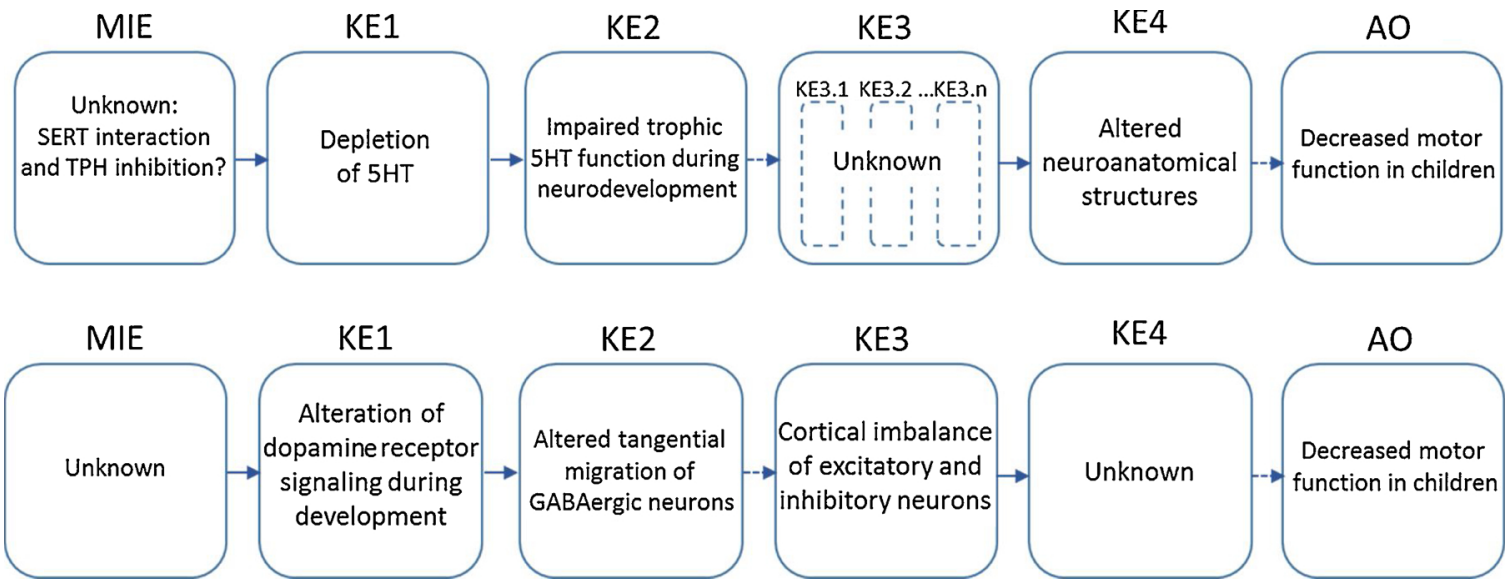

Fig. 5. Hypothetical AOPs proposed from the data collection of this systematic review. (A) This AOP describes the interference of a compound with the serotonin transporter and enzyme synthesis during brain development leading to decreased motor functions in children. (B) The second AOP describes alteration of DA receptor signaling during development leading to a cortical imbalance of excitatory and inhibitory neurons in cortex causing decreased motor functinos in children.

compound PCPA leads to locomotor deficits (Vinay et al., 2005) linking this KE2 to an AO in animals. Supporting this link, neonatal intraventricular injections of the selective serotonin neurotoxin 5,7-dihydroxytryptamine (5,7-DHT) leading to serotonin depletion in frontal cortex, hippocampus and striatum, also produced a reduction in locomotor activity in rats (Rok-Bujko et al., 2012). Serotonin deficiency during development causes alterations in neuroanatomical structures (KE4), one of them disturbing the development of brain stem projections into the lumbar enlargement of the spinal cord, resulting in poorer motor control (Vinay et al., 2005). If these disturbances are the reason for the AO seen after MDMA exposure in humans (KE4R to the human AO) is currently unknown. Over all, this is a hypothetical AOP with a high amount of uncertainty.

The second hypothetical AOP (Fig. 5) involves the dopaminergic system and has even less supportive evidence than the first one. Here, altered DA receptor signaling during development alters amongst others tangential migration of GABAergic neurons possibly resulting in inappropriate neuronal excitation-inhibition balance in cortex, which could change motor activity. For example, the hyperdopaminergic DA transporter knockout mouse displays the behavioural phenotype of hyperactivity (Money and Stanwood, 2013). Much more data is needed to fill the gaps of this hypothetical AOP.

This exercise revealed that there are huge data gaps in the understanding of basic biology as well as MDMA toxicology. There is no consistent evidence that links the adverse effects of MDMA across the different levels of organisations: cellular, organ and organism. From the AO point of view, postnatal exposure in rodents seems to reflect MDMA effects in exposed humans better than prenatal exposure. The reason for this and for the opposite effects seen after pre- and postnatal exposure in rodents are not known. Research needs for fully understanding how MDMA causes which adverse effects in humans should include further mechanistic in vitro studies, preferably in human developing brain cells, e.g. human induced pluripotent stem cell (hiPSC)-derived neural cells, or in alternative whole organisms, which allow the combination of mechanistic evaluations with behavioural assessments. Moreover, follow-up studies of prenatally exposed children is important because the transmitter systems altered by MDMA, i.e. the NE, DA and serotonergic systems, also determine psychiatric diseases later in life. Clearly more data are needed that shed light on the mechanisms and consequences of prenatal MDMA exposure in humans.

\section{Declaration of Competing Interest}

The authors declare that they have no known competing financial interests or personal relationships that could have appeared to influence the work reported in this paper.

\section{Appendix A. Supplementary data}

Supplementary material related to this article can be found, in the online version, at doi:https://doi.org/10.1016/j.neuro.2019.12.007.

\section{References}

Aguirre, N., Barrionuevo, M., Lasheras, B., Del Rio, J., 1998. The role of dopaminergic systems in the perinatal sensitivity to 3, 4-methylenedioxymethamphetamine-induced neurotoxicity in rats. J. Pharmacol. Exp. Ther. 286, 1159-1165.

Ankley, G.T., Bennett, R.S., Erickson, R.J., Hoff, D.J., Hornung, M.W., Johnson, R.D., Mount, D.R., Nichols, J.W., Russom, C.L., Schmieder, P.K., Serrrano, J.A., Tietge, J.E., Villeneuve, D.L., 2010. Adverse outcome pathways: a conceptual framework to support ecotoxicology research and risk assessment. Environ. Toxicol. Chem. 29, 730-741. https://doi.org/10.1002/etc.34.

Aschner, M., Ceccatelli, S., Daneshian, M., Fritsche, E., Hasiwa, N., Hartung, T., Hogberg, H.T., Leist, M., Li, A., Mundi, W.R., Padilla, S., Piersma, A.H., Bal-Price, A., Seiler, A. Westerink, R.H., Zimmer, B., Lein, P.J., 2017. Reference compounds for alternative test methods to indicate developmental neurotoxicity (DNT) potential of chemicals: example lists and criteria for their selection and use. ALTEX 34, 49-74. https://doi. org/10.14573/altex.1604201.

Bailey, B.A., Sokol, R.J., 2011. Prenatal alcohol exposure and miscarriage, stillbirth, preterm delivery, and sudden infant death syndrome. Alcohol Res. Heal. J. Natl. Inst. Alcohol Abus. Alcohol. 34, 86-91.

Bal-Price, A., Lein, P.J., Keil, K.P., Sethi, S., Shafer, T., Barenys, M., Fritsche, E., Sachana, M., Meek, M.E., 2017. Developing and applying the adverse outcome pathway 
concept for understanding and predicting neurotoxicity. Neurotoxicology 59 240-255. https://doi.org/10.1016/j.neuro.2016.05.010.

Barenys, M., Gomez-Catalan, J., Camps, L., Teixido, E., de Lapuente, J., Gonzalez-Linares, J., Serret, J., Borras, M., Rodamilans, M., Llobet, J.M., 2010. MDMA (ecstasy) delays pubertal development and alters sperm quality after developmental exposure in the rat. Toxicol. Lett. 197, 135-142. https://doi.org/10.1016/j.toxlet.2010.05.009.

Bissonette, G.B., Roesch, M.R., 2016. Development and function of the midbrain dopamine system: what we know and what we need to. Genes Brain Behav. 15, 62-73. https://doi.org/10.1111/gbb.12257.

Bogdanova, O.V., Kanekar, S., D’Anci, K.E., Renshaw, P.F., 2013. Factors influencing behavior in the forced swim test. Physiol. Behav. 118, 227-239. https://doi.org/10. 1016/j.physbeh.2013.05.012.

Broening, H.W., Bacon, L., Slikker Jr., W., 1994. Age modulates the long-term but not the acute effects of the serotonergic neurotoxicant 3,4-methylenedioxymethamphetamine. J. Pharmacol. Exp. Ther. 271, 285-293.

Broening, H.W., Bowyer, J.F., Slikker Jr., W., 1995. Age-dependent sensitivity of rats to the long-term effects of the serotonergic neurotoxicant (+/-)-3,4-methylenedioxymethamphetamine (MDMA) correlates with the magnitude of the MDMA-induced thermal response. J. Pharmacol. Exp. Ther. 275, 325-333.

Broening, H.W., Morford, L.L., Inman-Wood, S.L., Fukumura, M., Vorhees, C.V., 2001. 3,4-methylenedioxymethamphetamine (ecstasy)-induced learning and memory impairments depend on the age of exposure during early development. J. Neurosci. 21, 3228-3235.

Brummelte, S., Mc Glanaghy, E., Bonnin, A., Oberlander, T.F., 2017. Developmental changes in serotonin signaling: implications for early brain function, behavior and adaptation. Neuroscience 342, 212-231. https://doi.org/10.1016/j.neuroscience. 2016.02.037.

Campbell, N.G., Koprich, J.B., Kanaan, N.M., Lipton, J.W., 2006. MDMA administration to pregnant Sprague-Dawley rats results in its passage to the fetal compartment. Neurotoxicol. Teratol. 28, 459-465. https://doi.org/10.1016/j.ntt.2006.05.006.

Canales, J.J., Ferrer-Donato, A., 2014. Prenatal exposure to alcohol and 3,4-methylenedioxymethamphetamine (ecstasy) alters adult hippocampal neurogenesis and causes enduring memory deficits. Dev. Neurosci. 36, 10-17. https://doi.org/10.1159/ 000356820.

Capela, J.P., Carmo, H., Remiao, F., Bastos, M.L., Meisel, A., Carvalho, F., 2009. Molecular and cellular mechanisms of ecstasy-induced neurotoxicity: an overview. Mol. Neurobiol. 39, 210-271. https://doi.org/10.1007/s12035-009-8064-1.

Castilla, J., Barrio, G., Belza, M.J., de la Fuente, L., 1999. Drug and alcohol consumption and sexual risk behaviour among young adults: results from a national survey. Drug Alcohol Depend. 56, 47-53.

ChemIDplus, ChemIDplus [WWW Document]. URL https://chem.nlm.nih.gov/ chemidplus/chemidlite.jsp.

Cho, K.O., Rhee, G.S., Kwack, S.J., Chung, S.Y., Kim, S.Y., 2008. Developmental exposure to 3,4-methylenedioxymethamphetamine results in downregulation of neurogenesis in the adult mouse hippocampus. Neuroscience 154, 1034-1041. https://doi.org/10. 1016/j.neuroscience.2008.04.040.

Chudley, A.E., Conry, J., Cook, J.L., Loock, C., Rosales, T., Leblanc, N., 2005. Fetal alcohol spectrum disorder: Canadian guidelines for diagnosis. Spectrum 172.

Clancy, B., Darlington, R.B., Finlay, B.L., 2001. Translating developmental time across mammalian species. Neuroscience 105, 7-17.

Clancy, B., Finlay, B.L., Darlington, R.B., Anand, K.J.S., 2007. Extrapolating brain development from experimental species to humans. Neurotoxicology 28, 931-937. https://doi.org/10.1016/j.neuro.2007.01.014.

Cohen, M.A., Skelton, M.R., Schaefer, T.L., Gudelsky, G.A., Vorhees, C.V., Williams, M.T., 2005. Learning and memory after neonatal exposure to 3,4-methylenedioxymethamphetamine (ecstasy) in rats: interaction with exposure in adulthood. Synapse 57, 148-159. https://doi.org/10.1002/syn.20166.

Colado, M.I., O'Shea, E., Granados, R., Misra, A., Murray, T.K., Green, A.R., 1997. A study of the neurotoxic effect of MDMA ('ecstasy') on 5-HT neurones in the brains of mothers and neonates following administration of the drug during pregnancy. Br. J. Pharmacol. 121, 827-833. https://doi.org/10.1038/sj.bjp.0701201.

Compton, W.M., Thomas, Y.F., Stinson, F.S., Grant, B.F., 2007. Prevalence, correlates, disability, and comorbidity of DSM-IV drug abuse and dependence in the United States: results from the national epidemiologic survey on alcohol and related conditions. Arch. Gen. Psychiatry 64, 566-576. https://doi.org/10.1001/archpsyc.64.5. 566.

Counts, S., Mufson, E., 2012. Locus coeruleus. The Human Nervous System. pp. 425-438. https://doi.org/10.1016/B978-0-12-374236-0.10012-4.

DART, DART - ToxNet.

Darvesh, A.S., Gudelsky, G.A., 2004. The relationship between hyperthermia and glycogenolysis in 3,4-methylenedioxymethamphetamine-induced serotonin depletion in rats. Neurotoxicol. Teratol. 26, 571-577. https://doi.org/10.1016/j.ntt.2004.03.008.

de la Torre, R., Farre, M., Ortuno, J., Mas, M., Brenneisen, R., Roset, P.N., Segura, J. Cami, J., 2000. Non-linear pharmacokinetics of MDMA ('ecstasy') in humans. Br. J. Clin. Pharmacol. 49, 104-109.

Dzietko, M., Sifringer, M., Klaus, J., Endesfelder, S., Brait, D., Hansen, H.H., Bendix, I.,
Felderhoff-Mueser, U., 2010. Neurotoxic effects of MDMA (ecstasy) on the developing rodent brain. Dev. Neurosci. 32, 197-207. https://doi.org/10.1159/000313473.

Ellegood, J., Yee, Y., Kerr, T.M., Muller, C.L., Blakely, R.D., Henkelman, R.M., VeenstraVanderWeele, J., Lerch, J.P., 2018. Analysis of neuroanatomical differences in mice with genetically modified serotonin transporters assessed by structural magnetic resonance imaging. Mol. Autism 9, 24. https://doi.org/10.1186/s13229-018-0210-z.

EMCDDA, 2017. European Drug Report. European Union Publications Officehttps://doi. org/10.1097/JSM.0b013e31802b4fda.

EMCDDA, 2012. Pregnancy, Childcare and the Family: Key Issues for Europe's Response to Drugs.

Environmental Protection Agency, 1991. Guidelines for Developmental Toxicity Risk Assessment. Risk Assessment Forum.

Eun, J.W., Kwack, S.J., Noh, J.H., Jung, K.H., Kim, J.K., Bae, H.J., Xie, H., Ryu, J.C., Ahn, Y.M., Park, W.S., Lee, J.Y., Rhee, G.S., Nam, S.W., 2010. Identification of post-generation effect of 3,4-methylenedioxymethamphetamine on the mouse brain by largescale gene expression analysis. Toxicol. Lett. 195, 60-67. https://doi.org/10.1016/j. toxlet.2010.02.013.

Forray, A., 2016. Substance use during pregnancy. F1000Research 5. https://doi.org/10. 12688/f1000research.7645.1.

Galineau, L., Belzung, C., Kodas, E., Bodard, S., Guilloteau, D., Chalon, S., 2005. Prenatal 3,4-methylenedioxymethamphetamine (ecstasy) exposure induces long-term alterations in the dopaminergic and serotonergic functions in the rat. Brain Res. Dev. Brain Res. 154, 165-176. https://doi.org/10.1016/j.devbrainres.2004.10.012.

Green, A.R., Gabrielsson, J., Marsden, C.A., Fone, K.C.F., 2009. MDMA: on the translation from rodent to human dosing. Psychopharmacology (Berl.) 204, 375-378. https:// doi.org/10.1007/s00213-008-1453-8.

Green, A.R., Mechan, A.O., Elliott, J.M., O'Shea, E., Colado, M.I., 2003. The pharmacology and clinical pharmacology of 3,4-methylenedioxymethamphetamine (MDMA, “ecstasy"). Pharmacol. Rev. 55, 463-508. https://doi.org/10.1124/pr.55.3.3.

Hasenhuetl, P.S., Bhat, S., Mayer, F.P., Sitte, H.H., Freissmuth, M., Sandtner, W., 2018. A kinetic account for amphetamine-induced monoamine release. J. Gen. Physiol. https://doi.org/10.1085/jgp.201711915.

Heuland, E., Germaux, M.A., Galineau, L., Chalon, S., Belzung, C., 2010. Prenatal MDMA exposure delays postnatal development in the rat: a preliminary study. Neurotoxicol. Teratol. 32, 425-431. https://doi.org/10.1016/j.ntt.2010.03.006.

Ho, E., Karimi-Tabesh, L., Koren, G., 2001. Characteristics of pregnant women who use Ecstasy (3,4-methylenedioxymethamphetamine). Teratology 63, 280.

Jepma, M., Deinum, J., L Asplund, C., Rombouts, S., T Tamsma, J., Tjeerdema, N., Spapé, M., Garland, E., Robertson, D., Wm Lenders, J., Nieuwenhuis, S., 2011 Neurocognitive function in Dopamine- $\beta$-hydroxylase deficiency. Neuropsychopharmacology 36, 1608-1619. https://doi.org/10.1038/npp.2011.42.

Kaizaki, A., Tanaka, S., Yoshida, T., Numazawa, S., 2014. Maternal MDMA administration in mice leads to neonatal growth delay. J. Toxicol. Sci. 39, 33-39.

Keating, E., Gonçalves, P., Campos, I., Costa, F., Azevedo, I., Martel, F., 2007. Effect of pathological conditions, pharmacotherapy and drugs of abuse upon folic acid placental uptake. FASEB J. 21.

Keating, E., Goncalves, P., Campos, I., Costa, F., Martel, F., 2009. Folic acid uptake by the human syncytiotrophoblast: interference by pharmacotherapy, drugs of abuse and pathological conditions. Reprod. Toxicol. 28, 511-520. https://doi.org/10.1016/j. reprotox.2009.07.001.

Kelly, P.A., Ritchie, I.M., Quate, L., McBean, D.E., Olverman, H.J., 2002. Functional consequences of perinatal exposure to 3,4-methylenedioxymethamphetamine in rat brain. Br. J. Pharmacol. 137, 963-970. https://doi.org/10.1038/sj.bjp.0704961.

Klimisch, H.J., Andreae, M., Tillmann, U., 1997. A systematic approach for evaluating the quality of experimental toxicological and ecotoxicological data. Regul. Toxicol. Pharmacol. 25, 1-5. https://doi.org/10.1006/rtph.1996.1076.

Koprich, J.B., Campbell, N.G., Lipton, J.W., 2003a. Neonatal 3,4-methylenedioxymethamphetamine (ecstasy) alters dopamine and serotonin neurochemistry and increases brain-derived neurotrophic factor in the forebrain and brainstem of the rat. Brain Res. Dev. Brain Res. 147, 177-182.

Koprich, J.B., Chen, E.Y., Kanaan, N.M., Campbell, N.G., Kordower, J.H., Lipton, J.W. 2003b. Prenatal 3,4-methylenedioxymethamphetamine (ecstasy) alters exploratory behavior, reduces monoamine metabolism, and increases forebrain tyrosine hydroxylase fiber density of juvenile rats. Neurotoxicol. Teratol. 25, 509-517.

Kwack, S.J., Yoon, K.S., Lim, S.K., Gwak, H.M., Kim, J.Y., Um, Y.M., Lee, J.D., Hyeon, J.H., Kim, Y.J., Kim, H.S., Lee, B.M., 2014. A one-generation reproductive toxicity study of 3,4-methylenedioxy-n-methamphetamine (MDMA, Ecstasy), an amphetamine derivative, in C57BL/6 mice. J. Toxicol. Environ. Heal. A 77, 1431-1442. https://doi.org/10.1080/15287394.2014.951759.

Lipton, J.W., Tolod, E.G., Thompson, V.B., Pei, L., Paumier, K.L., Terpstra, B.T., Lynch, K.A., Collier, T.J., Sortwell, C.E., 2008. 3,4-Methylenedioxy-N-methamphetamine (ecstasy) promotes the survival of fetal dopamine neurons in culture. Neuropharmacology 55, 851-859. https://doi.org/10.1016/j.neuropharm.2008.06. 062.

Mattison, A.M., Ross, M.W., Wolfson, T., Franklin, D., 2001. Circuit party attendance, club drug use, and unsafe sex in gay men. J. Subst. Abuse 13, 119-126. 
May, A.L., Parrott, A.C., 2015. Greater sexual risk-taking in female and male recreational MDMA/ecstasy users compared with alcohol drinkers: a questionnaire study. Hum. Psychopharmacol. 30, 272-275. https://doi.org/10.1002/hup.2432.

McDonnell-Dowling, K., Kelly, J.P., 2015. Sources of variation in the design of preclinical studies assessing the effects of amphetamine-type stimulants in pregnancy and lactation. Behav. Brain Res. 279, 87-99. https://doi.org/10.1016/j.bbr.2014.11.021.

Meamar, R., Karamali, F., Sadeghi, H.M., Etebari, M., Nasr-Esfahani, M.H., Baharvand, H., 2010. Toxicity of ecstasy (MDMA) towards embryonic stem cell-derived cardiac and neural cells. Toxicol. In Vitro 24, 1133-1138. https://doi.org/10.1016/j.tiv.2010.03. 005.

Meyer, J.S., Ali, S.F., 2002. Serotonergic neurotoxicity of MDMA (ecstasy) in the developing rat brain. Ann. N. Y. Acad. Sci. 965, 373-380.

Meyer, J.S., Grande, M., Johnson, K., Ali, S.F., 2004. Neurotoxic effects of MDMA ("ec stasy") administration to neonatal rats. Int. J. Dev. Neurosci. 22, 261-271. https:// doi.org/10.1016/j.ijdevneu.2004.04.007.

Mogensen, J., Pedersen, T.K., Holm, S., Bang, L.E., 1995. Prefrontal cortical mediation of rats' place learning in a modified water maze. Brain Res. Bull. 38, 425-434.

Money, K.M., Stanwood, G.D., 2013. Developmental origins of brain disorders: roles for dopamine. Front. Cell. Neurosci. 7, 260. https://doi.org/10.3389/fncel.2013.00260.

Moore, D.G., Turner, J.D., Parrott, A.C., Goodwin, J.E., Fulton, S.E., Min, M.O., Fox, H.C., Braddick, F.M., Axelsson, E.L., Lynch, S., Ribeiro, H., Frostick, C.J., Singer, L.T., 2010. During pregnancy, recreational drug-using women stop taking ecstasy $(3,4-$ methylenedioxy-N-methylamphetamine) and reduce alcohol consumption, but continue to smoke tobacco and cannabis: initial findings from the Development and Infancy Study. J. Psychopharmacol. 24, 1403-1410. https://doi.org/10.1177/ 0269881109348165.

Morris, R.G., Garrud, P., Rawlins, J.N., O’Keefe, J., 1982. Place navigation impaired in rats with hippocampal lesions. Nature 297, 681-683.

Mueller, M., Maldonado-Adrian, C., Yuan, J., McCann, U.D., Ricaurte, G.A., 2013. Studies of ( \pm )-3,4-methylenedioxymethamphetamine (MDMA) metabolism and disposition in rats and mice: relationship to neuroprotection and neurotoxicity profile. J. Pharmacol. Exp. Ther. 344, 479-488. https://doi.org/10.1124/jpet.112.201699.

O'Callaghan, J.P., Miller, D.B., 1994. Neurotoxicity profiles of substituted amphetamines in the C57BL/6J mouse. J. Pharmacol. Exp. Ther. 270, 741-751.

Page, M.E., Detke, M.J., Dalvi, A., Kirby, L.G., Lucki, I., 1999. Serotonergic mediation of the effects of fluoxetine, but not desipramine, in the rat forced swimming test. Psychopharmacology (Berl) 147, 162-167.

Palamar, J.J., Griffin-Tomas, M., Acosta, P., Ompad, D.C., Cleland, C.M., 2018. A comparison of self-reported sexual effects of alcohol, marijuana, and ecstasy in a sample of young adult nightlife attendees. Psychol. Sex. 9, 54-68. https://doi.org/10.1080/ 19419899.2018.1425220.

Parrott, A.C., 2013. Human psychobiology of MDMA or "Ecstasy": an overview of 25 years of empirical research. Hum. Psychopharmacol. 28, 289-307. https://doi.org/ 10.1002/hup.2318.

Petrangelo, A., Czuzoj-Shulman, N., Balayla, J., Abenhaim, H.A., 2018. Cannabis abuse or dependence during pregnancy: a population-based cohort study on 12 million births. J. Obstet. Gynaecol. Can. https://doi.org/10.1016/j.jogc.2018.09.009.

Piper, B.J., Farelli, J.D., Meyer, J.S., 2009. Dissociation between serotonin neurotoxicity and brain-derived neurotrophic factor induction following neonatal MDMA exposure in rats. Dev. Neurosci. 31, 90-94. https://doi.org/10.1159/000207497.

Piper, B.J., Meyer, J.S., 2006. Increased responsiveness to MDMA in adult rats treated neonatally with MDMA. Neurotoxicol. Teratol. 28, 95-102. https://doi.org/10.1016/ j.ntt.2005.09.002

PubMed, PubMed [WWW Document]. URL https://www.ncbi.nlm.nih.gov/pubmed.

Richter-Levin, G., Acsady, L., Freund, T.F., Segal, M., 1994. Differential effects of serotonin and raphe grafts in the hippocampus and hypothalamus: a combined behavioural and anatomical study in the rat. Eur. J. Neurosci. 6, 1720-1728.

Rok-Bujko, P., Krzascik, P., Szyndler, J., Kostowski, W., Stefanski, R., 2012. The influence of neonatal serotonin depletion on emotional and exploratory behaviours in rats. Behav. Brain Res. 226, 87-95. https://doi.org/10.1016/j.bbr.2011.08.030.

Schaefer, T.L., Ehrman, L.A., Gudelsky, G.A., Vorhees, C.V., Williams, M.T., 2006. Comparison of monoamine and corticosterone levels $24 \mathrm{~h}$ following $(+)$ methamphetamine, $(+/-) 3,4$-methylenedioxymethamphetamine, cocaine, $(+)$ fenfluramine or $(+/-)$ methylphenidate administration in the neonatal rat. J. Neurochem. 98 , 1369-1378. https://doi.org/10.1111/j.1471-4159.2006.04034.x.

Schaefer, T.L., Grace, C.E., Braun, A.A., Amos-Kroohs, R.M., Graham, D.L., Skelton, M.R., Williams, M.T., Vorhees, C.V., 2013. Cognitive impairments from developmental exposure to serotonergic drugs: citalopram and MDMA. Int. J. Neuropsychopharmacol. 16, 1383-1394. https://doi.org/10.1017/ s1461145712001447.

Schaefer, T.L., Grace, C.E., Skelton, M.R., Graham, D.L., Gudelsky, G.A., Vorhees, C.V., Williams, M.T., 2012. Neonatal citalopram treatment inhibits the 5-HT depleting effects of MDMA exposure in rats. ACS Chem. Neurosci. 3, 12-21. https://doi.org/10. $1021 /$ cn2000553.

Schaefer, T.L., Skelton, M.R., Herring, N.R., Gudelsky, G.A., Vorhees, C.V., Williams, M.T., 2008. Short- and long-term effects of (+)-methamphetamine and (+/-)-3,4 methylenedioxymethamphetamine on monoamine and corticosterone levels in the neonatal rat following multiple days of treatment. J. Neurochem. 104, 1674-1685. https://doi.org/10.1111/j.1471-4159.2007.05112.x.

Schneider, K., Schwarz, M., Burkholder, I., Kopp-Schneider, A., Edler, L., KinsnerOvaskainen, A., Hartung, T., Hoffmann, S., 2009. "ToxRTool", a new tool to assess the reliability of toxicological data. Toxicol. Lett. 189, 138-144. https://doi.org/10. 1016/j.toxlet.2009.05.013.

Scott, K., Fagermo, N., Callaway, L., Lust, K., 2010. Illicit drug use in late pregnancy associated with stillbirth and eclampsia. Obs. Med. 3, 113-114. https://doi.org/10. 1258/om.2010.090061.

Sevy, S., Papadimitriou, G.N., Surmont, D.W., Goldman, S., Mendlewicz, J., 1989. Noradrenergic function in generalized anxiety disorder, major depressive disorder, and healthy subjects. Biol. Psychiatry 25, 141-152.

Shah, R., Courtiol, E., Castellanos, F.X., Teixeira, C.M., 2018. Abnormal serotonin levels during perinatal development lead to behavioral deficits in adulthood. Front. Behav. Neurosci. 12, 114. https://doi.org/10.3389/fnbeh.2018.00114.

Singer, L.T., Moore, D.G., Fulton, S., Goodwin, J., Turner, J.J.D., Min, M.O., Parrott, A.C., 2012a. Neurobehavioral outcomes of infants exposed to MDMA (Ecstasy) and other recreational drugs during pregnancy. Neurotoxicol. Teratol. 34, 303-310. https:// doi.org/10.1016/j.ntt.2012.02.001.

Singer, L.T., Moore, D.G., Min, M.O., Goodwin, J., Turner, J.J.D., Fulton, S., Parrott, A.C., 2016. Motor delays in MDMA (ecstasy) exposed infants persist to 2years. Neurotoxicol. Teratol. 54, 22-28. https://doi.org/10.1016/j.ntt.2016.01.003.

Singer, L.T., Moore, D.G., Min, M.O., Goodwin, J., Turner, J.J.D., Fulton, S., Parrott, A.C., 2012b. One-year outcomes of prenatal exposure to MDMA and other recreational drugs. Pediatrics 130, 407-413. https://doi.org/10.1542/peds.2012-0666.

Skelton, M.R., Graham, D.L., Schaefer, T.L., Grace, C.E., Braun, A.A., Burns, L.N., Amos Kroohs, R.M., Williams, M.T., Vorhees, C.V., 2012. Distinct periods of developmental sensitivity to the effects of 3,4-(+/-)-methylenedioxymethamphetamine (MDMA) on behaviour and monoamines in rats. Int. J. Neuropsychopharmacol. 15, 811-824. https://doi.org/10.1017/s1461145711000952.

St Omer, V.E., Ali, S.F., Holson, R.R., Duhart, H.M., Scalzo, F.M., Slikker Jr., W., 1991. Behavioral and neurochemical effects of prenatal methylenedioxymethamphetamine (MDMA) exposure in rats. Neurotoxicol. Teratol. 13, 13-20.

Steele, T.D., McCann, U.D., Ricaurte, G.A., 1994. 3,4-Methylenedioxymethamphetamine (MDMA, "Ecstasy"): pharmacology and toxicology in animals and humans. Addiction 89, 539-551.

Substance Abuse and Mental Health Services Administration, 2018. Results From the 2017 National Survey on Drug Use and Health. Vol. I. Summ. Natl. Find. .

Substance Abuse and Mental Health Services Administration, 2009. Results From the 2008 National Survey on Drug Use and Health: National Findings: Full Report and Detailed Tables.

Suri, D., Teixeira, C.M., Cagliostro, M.K.C., Mahadevia, D., Ansorge, M.S., 2015 Monoamine-sensitive developmental periods impacting adult emotional and cognitive behaviors. Neuropsychopharmacology 40, 88-112. https://doi.org/10.1038/ npp.2014.231.

Thomas, S.A., Palmiter, R.D., 1997. Disruption of the dopamine beta-hydroxylase gene in mice suggests roles for norepinephrine in motor function, learning, and memory. Behav. Neurosci. 111, 579-589.

Thompson, V.B., Heiman, J., Chambers, J.B., Benoit, S.C., Buesing, W.R., Norman, M.K., Norman, A.B., Lipton, J.W., 2009. Long-term behavioral consequences of prenatal MDMA exposure. Physiol. Behav. 96, 593-601. https://doi.org/10.1016/j.physbeh. 2008.12.013.

Thompson, V.B., Koprich, J.B., Chen, E.Y., Kordower, J.H., Terpstra, B.T., Lipton, J.W., 2012. Prenatal exposure to MDMA alters noradrenergic neurodevelopment in the rat Neurotoxicol. Teratol. 34, 206-213. https://doi.org/10.1016/j.ntt.2011.09.005.

Travis, K., Schnatter, R., Swaen, G., Money, C., Pallapies, D., Priem, P., Onyon, L., 2008. A proposed framework for the integration of human and animal data in chemical risk assessment. Toxicol. Lett. 180, S19-S20. https://doi.org/10.1016/j.toxlet.2008.06. 729.

Tsuji, R., Crofton, K.M., 2012. Developmental neurotoxicity guideline study: issues with methodology, evaluation and regulation. Congenit. Anom. (Kyoto) 52, 122-128. https://doi.org/10.1111/j.1741-4520.2012.00374.x.

Van, T.M.R., Garbis, H., Reuvers, M., 1998. Ecstasy exposure during pregnancy. Teratology 58.

Vinay, L., Ben-Mabrouk, F., Brocard, F., Clarac, F., Jean-Xavier, C., Pearlstein, E., Pflieger, J.-F., 2005. Perinatal development of the motor systems involved in postural control. Neural Plast. 12, 131-139. https://doi.org/10.1155/np.2005.131.

Vorhees, C.V., Reed, T.M., Skelton, M.R., Williams, M.T., 2004. Exposure to 3,4-methylenedioxymethamphetamine (MDMA) on postnatal days 11-20 induces reference but not working memory deficits in the Morris water maze in rats: implications of prior learning. Int. J. Dev. Neurosci. 22, 247-259. https://doi.org/10.1016/j.ijdevneu. 2004.06.003.

Vorhees, C.V., Schaefer, T.L., Skelton, M.R., Grace, C.E., Herring, N.R., Williams, M.T., 2009. (+/-)3,4-Methylenedioxymethamphetamine (MDMA) dose-dependently impairs spatial learning in the morris water maze after exposure of rats to different five- 
day intervals from birth to postnatal day twenty. Dev. Neurosci. 31, 107-120. https://doi.org/10.1159/000207499.

WebofScience, 2019. Web of Science [WWW Document]. URL. https://www. webofknowledge.com.

Whishaw, I.Q., Mittleman, G., Bunch, S.T., Dunnett, S.B., 1987. Impairments in the acquisition, retention and selection of spatial navigation strategies after medial caudate-putamen lesions in rats. Behav. Brain Res. 24, 125-138.
Williams, M.T., Skelton, M.R., Longacre, I.D., Huggins, K.N., Maple, A.M., Vorhees, C.V., Brown, R.W., 2014. Neuronal reorganization in adult rats neonatally exposed to (+/-)-3,4-methylenedioxymethamphetamine. Toxicol. Rep. 1, 699-706. https://doi. org/10.1016/j.toxrep.2014.08.018.

Wyatt, R.J., Portnoy, B., Kupfer, D.J., Snyder, F., Engelman, K., 1971. Resting plasma catecholamine concentrations in patients with depression and anxiety. Arch. Gen. Psychiatry 24, 65-70. 